\title{
Application of WRF/Chem over North America under the AQMEII Phase 2 - Part 2: Evaluation of 2010 application and responses of air quality and meteorology-chemistry interactions to changes in emissions and meteorology from 2006 to 2010
}

\author{
K. Yahya ${ }^{1}$, K. Wang ${ }^{1}$, Y. Zhang ${ }^{1}$, and T. E. Kleindienst ${ }^{2}$ \\ ${ }^{1}$ Department of Marine, Earth, and Atmospheric Sciences, NCSU, Raleigh, NC 27695, USA \\ ${ }^{2}$ National Exposure Research Laboratory, U.S. EPA, Research Triangle Park, NC 27711, USA \\ Correspondence to: Y. Zhang (yzhang9@ncsu.edu)
}

Received: 23 December 2014 - Published in Geosci. Model Dev. Discuss.: 19 February 2015

Revised: 15 May 2015 - Accepted: 4 June 2015 - Published: 16 July 2015

\begin{abstract}
The Weather Research and Forecasting model with Chemistry (WRF/Chem) simulation with the 2005 Carbon Bond (CB05) gas-phase mechanism coupled to the Modal for Aerosol Dynamics for Europe (MADE) and the volatility basis set approach for secondary organic aerosol (SOA) are conducted over a domain in North America for 2006 and 2010 as part of the Air Quality Model Evaluation International Initiative (AQMEII) Phase 2 project. Following the Part 1 paper that focuses on the evaluation of the 2006 simulations, this Part 2 paper focuses on a comparison of model performance in 2006 and 2010 as well as analysis of the responses of air quality and meteorologychemistry interactions to changes in emissions and meteorology from 2006 to 2010. In general, emissions for gaseous and aerosol species decrease from 2006 to 2010, leading to a reduction in gaseous and aerosol concentrations and associated changes in radiation and cloud variables due to various feedback mechanisms. WRF/Chem is able to reproduce most observations and the observed variation trends from 2006 to 2010, despite its slightly worse performance than WRF that is likely due to inaccurate chemistry feedbacks resulting from less accurate emissions and chemical boundary conditions (BCONs) in 2010. Compared to 2006, the performance for most meteorological variables in 2010 gives lower normalized mean biases but higher normalized mean errors and lower correlation coefficients. The model also shows poorer performance for most chemical variables in 2010 . This could be attributed to underestimations in emissions of some species, such as primary organic aerosol in some ar-
\end{abstract}

eas of the US in 2010, and inaccurate chemical BCONs and meteorological predictions. The inclusion of chemical feedbacks in WRF/Chem reduces biases in meteorological predictions in 2010; however, it increases errors and weakens correlations comparing to WRF simulations. Sensitivity simulations show that the net changes in meteorological variables from 2006 to 2010 are mostly influenced by changes in meteorology and those of ozone and fine particulate matter are influenced to a large extent by emissions and/or chemical BCONs and to a lesser extent by changes in meteorology. Using a different set of emissions and/or chemical BCONs helps improve the performance of individual variables, although it does not improve the degree of agreement with observed interannual trends. These results indicate a need to further improve the accuracy and consistency of emissions and chemical BCONs, the representations of SOA and chemistry-meteorology feedbacks in the online-coupled models.

\section{Introduction}

Changes in meteorology, climate, and emissions affect air quality (e.g., Hogrefe et al., 2004; Leung and Gustafson, 2005; Zhang et al., 2008; Dawson et al., 2009; Gao et al., 2013; Penrod et al., 2014). As federal, state, and local environmental protection agencies enforce the anthropogenic emission control programs, ambient air quality is expected to be continuously improved. However, such an improvement 
may be compensated by adverse changes in climatic or meteorological conditions (e.g., increases in near-surface temperature, solar radiation, and atmospheric stability, or reductions in precipitation) that are directly conducive to the formation and accumulation of air pollutants and that may result in higher biogenic emissions. It is therefore important to examine changes in meteorology/climate and emissions as well as their combined impacts on air quality. The Air Quality Model Evaluation International Initiative (AQMEII) Phase 2 was launched in 2011 to intercompare online-coupled air quality models (AQMs) in their capabilities in reproducing atmospheric observations and simulating air quality and climate interactions in North America (NA) and Europe (EU) (Alapaty et al., 2012). The simulations over NA and EU with multimodels by a number of participants have been performed for 2 years (2006 and 2010) that have distinct meteorological conditions. Compared with 2006, 2010 is characterized by warmer summer conditions in the eastern US and less precipitation over NA (Stoeckenius et al., 2015; Pouliot et al., 2014). In addition, the emissions of key pollutants are reduced in 2010 relative to 2006, e.g., emissions of oxides of nitrogen $\left(\mathrm{NO}_{x}\right)$ and sulfur dioxide $\left(\mathrm{SO}_{2}\right)$ are reduced by $10-30$ and $40-80 \%$ for many regions in NA (Pouliot et al., 2014). Comparison of 2010 and 2006 simulations will thus provide an opportunity to examine the success of the emission control programs and the impacts of meteorologi$\mathrm{cal} / \mathrm{climatic}$ variables on air quality. Compared to model intercomparison during AQMEII Phase 1 (Rao et al., 2012) in which offline-coupled models were used, the use of onlinecoupled AQMs during AQMEII Phase 2 allows for study of the interactions between meteorology and chemistry through various direct and indirect feedbacks among aerosols, radiation, clouds, and chemistry (Zhang, 2008; Baklanov et al., 2014). The 2-year simulations further enable an examination of the responses of air quality and meteorology-chemistry interactions to changes in emissions and meteorology from 2006 to 2010 that was not possible with offline-coupled models.

Similar to offline AQMs, large uncertainties exist in online-coupled AQMs, which will affect the model predictions and implications. Such uncertainties lie in the meteorological and chemical inputs such as emissions, initial and boundary conditions (ICONs and BCONs), model representations of atmospheric processes, and model configurations for applications such as horizontal/vertical grid resolutions and nesting techniques. Several studies examined the uncertainties in emissions (e.g., Reid et al., 2005; Zhang et al., 2014) and BCONs (e.g., Hogrefe et al., 2004; Schere et al., 2012). There are also uncertainties in various chemical mechanisms and physical parameterizations used in AQMs such as gas-phase mechanisms (Zhang et al., 2012), aerosol chemistry and microphysical treatments (Zhang et al., 2010), microphysical parameterizations (van Lier-Walqui et al., 2014), convective parameterizations (Yang et al., 2013), boundary layer schemes (Edwards et al., 2006), and land surface models (Jin et al., 2010). Due to the complex relationships in online-coupled AQMs among the emissions, ICONs and $\mathrm{BCONs}$, and model processes that may be subject to inherent limitations, it is difficult to isolate the contributions of model inputs or the representations of atmospheric processes to the model biases. In mechanistic evaluation (also referred to as dynamic evaluation), sensitivity simulations are performed by changing one or a few model inputs or process treatments, while holding others constant. This approach can help diagnose the likely sources of biases in the model predictions.

The Weather Research and Forecasting model with Chemistry (WRF/Chem) version 3.4.1 with the 2005 Carbon Bond (CB05) gas-phase mechanism coupled with the Modal for Aerosol Dynamics for Europe (MADE) and the volatility basis set (VBS) approach for secondary organic aerosol (SOA) (hereafter WRF/Chem-CB05-MADE/VBS) has been recently developed by Wang et al. (2014). The WRF/ChemCB05-MADE/VBS has been coupled to the aqueous-phase chemistry scheme (AQChem) based on the AQChem version in CMAQ v5.0 of Sarwar et al. (2011) for both largescale and convective clouds (Wang et al., 2014). WRF/ChemCB05-MADE/VBS also contains heterogeneous chemistry involving sulfur dioxide on the surface of aerosols based on Jacob (2000) and treats both aerosol direct and indirect effects. The applications of WRF/Chem-CB05-MADE/VBS to 2006 and 2010 in this work use the same model physical and chemical parameterizations as those in the Part 1 paper of Yahya et al. (2014) but with different emissions, meteorological ICONs and BCONs, and chemical ICONs and BCONs. The mechanistic evaluation by comparing WRF/Chem-CB05-MADE/VBS predictions for the 2 years would help in understanding the sensitivity of the model predictions and performance to different model inputs, and that by comparing WRF/Chem-CB05-MADE/VBS and WRFonly predictions would quantify the impacts of chemistrymeteorology feedbacks on the meteorological predictions. A comprehensive evaluation of the 2006 simulation has been presented in the Part 1 paper of Yahya et al. (2014). In this Part 2 paper, the differences in emissions, meteorological and chemical ICONs/BCONs, and meteorology between 2010 and 2006 are first examined briefly. The model performance in 2010 is then evaluated and compared with that in 2006 . Finally, the responses of air quality and meteorologychemistry interactions to changes in emissions, chemical ICONs/BCONs, and meteorology individually and collectively from 2006 to 2010 are analyzed. The main objectives of this Part 2 paper are to examine whether the model has the ability to consistently reproduce observations for two separate years, as well as to examine whether the trends in air quality and meteorology-chemistry interactions are consistent for both years. Stoeckenius et al. (2015) carried out an extensive analysis of the trends in emissions and observations of meteorological variables, $\mathrm{O}_{3}, \mathrm{SO}_{2}$, and $\mathrm{PM}_{2.5}$ concentrations between 2006 and 2010. This Part 2 paper complements the work of Stoeckenius et al. (2015) by examin- 
ing the changes in WRF/Chem predictions and chemistrymeteorology feedbacks in 2010 relative to 2006. Similar evaluations of 2010 and 2006 are performed for the coupled Weather Research and Forecasting - Community Multiscale Air Quality (WRF-CMAQ) system (Hogrefe et al., 2014). Unlike the coupled WRF-CMAQ system used in AQMEII Phase 2 that only simulates aerosol direct effects, WRF/Chem used in this work simulates both aerosol direct and indirect effects. In addition, the work by Hogrefe et al. (2014) involves nudging of temperature, wind speed, water vapor mixing ratio, soil temperature and soil moisture, while the model used for this study did not include any nudging.

\section{Differences in emissions and ICONs/BCONs between 2006 and 2010}

\subsection{Emission trends}

The emission variation trends are examined for major precursors for ozone $\left(\mathrm{O}_{3}\right)$ and secondary particulate matter (PM) (i.e., sulfur dioxide $\left(\mathrm{SO}_{2}\right)$, oxides of nitrogen $\left(\mathrm{NO}_{x}\right)$, ammonia $\left(\mathrm{NH}_{3}\right.$ ), volatile organic compounds (VOCs) including both anthropogenic and biogenic VOCs) and primary PM species (elemental carbon (EC) and primary organic aerosol or carbon (POA or POC)). As shown in Table S1 in the Supplement, emissions of most species decrease from 2006 to 2010 with domainwide averages of -10 to $-24 \%$. Comparing to emissions in 2006, the annual emissions of $\mathrm{SO}_{2}$ and $\mathrm{NO}_{x}$ decrease significantly in 2010, especially at the point sources (Fig. S1 in the Supplement), with similar variation patterns in all seasons (figure not shown). The annual emissions of $\mathrm{NH}_{3}$ decrease over most areas but increase in some areas in California (CA) and the midwest. Unlike the changes in the emissions of $\mathrm{SO}_{2}$ and $\mathrm{NO}_{x}, \mathrm{NH}_{3}$ and VOC emissions exhibit strong seasonal variations in the emission trends, as shown in Fig. S2. Although anthropogenic VOC emissions decrease over the continental US (CONUS) for all seasons (figure not shown), the VOC emissions increase in the southeast, which is dominated by enhanced biogenic emissions from vegetation as a response to temperature increases (Stoeckenius et al., 2015). The total annual emissions of EC and POA also decrease but to a smaller extent over most areas of the continental US. The changes in annual and seasonal emissions of those species between 2010 and 2006 will affect simulated air quality and meteorologychemistry interactions. In addition, there exist uncertainties in the NEI (National Emissions Inventory) emissions. The major sources of uncertainties or errors in the NEI emissions include (1) the emissions calculated using a bottom-up approach based on information provided by individual state, local, and tribal air agencies; and (2) improvements in emission estimation methodology over the years which may result in inconsistencies between years of NEI data (Xing et al., 2013). These will affect the accuracy of the model simulations.

\subsection{Differences in chemical and meteorological ICONs/BCONs}

Large differences exist in the chemical and meteorological ICONs/BCONs used in the simulations. For example, Stoeckenius et al. (2015) reported that the mid-tropospheric seasonal mean $\mathrm{O}_{3}$ mixing ratios are generally lower by several ppbs in 2010 as compared to 2006, especially during spring and summer. Less Asian mid-tropospheric fine dust was also transported over to the US in the spring of 2010 and less African dust reached the US in the summer of 2010 (Stoeckenius et al., 2015). As shown in Fig. S3, significant differences exist for January, February, and December (JFD) and June, July, and August (JJA) 2010-2006 in averaged meteorological ICONs and BCONs of skin temperature and soil moisture fractions $100-200 \mathrm{~cm}$ below ground extracted from the National Center of Environmental Prediction (NCEP).

\section{Model performance in 2010 and its comparison with 2006}

Model predictions in 2010 respond to changes in emissions, BCONs, and meteorology. The model performance for both meteorological and chemical predictions in 2010 is evaluated and compared with that in 2006. The surface observational networks used to evaluate 2010 results include the Clean Air Status and Trends Network - CASTNET (rural sites), the Southeastern Aerosol Research and Characterization - SEARCH (southeastern US only, rural and urban sites), the Speciated Trends Network - STN (urban sites), the Interagency Monitoring of Protected Visual Environments IMPROVE (rural sites), the Air Quality System - AQS (rural and urban sites) and the National Atmospheric Deposition Program - NADP (rural and urban sites). The satellite data used include the Moderate Resolution Imaging Spectroradiometer (MODIS) and Terra. The Global Precipitation Climatology Center (GPCC) for precipitation is a blend of rain gauge data, satellite data and reanalysis data. Major differences in model performance between the 2 years and their associations with changes in emissions, BCONs, and meteorology are discussed below.

\section{Differences in meteorological predictions for 2006 and 2010}

Table 1 shows the annual mean observed (Obs) and simulated (Sim) values as well as correlation coefficients (Corr) between the observed and simulated meteorological variables from the $2010 \mathrm{WRF} / \mathrm{Chem}$ and WRF simulations. Similar statistics from the $2006 \mathrm{WRF} / \mathrm{Chem}$ and WRF simulations can be found in Table 1 in Yahya et al. (2014). Figure 1 
Table 1. Annual performance statistics for 2010 Predictions of WRF and WRF/Chem.

\begin{tabular}{|c|c|c|c|c|c|c|c|c|c|c|c|}
\hline \multirow[b]{2}{*}{$\begin{array}{l}\text { Network } \\
\text { or site name }\end{array}$} & \multirow[b]{2}{*}{ Variable } & \multicolumn{3}{|c|}{ WRF } & \multirow[b]{2}{*}{$\begin{array}{r}\mathrm{NMB} \\
(\%)\end{array}$} & \multirow[b]{2}{*}{$\begin{array}{r}\text { NME } \\
(\%)\end{array}$} & \multicolumn{3}{|c|}{ WRF/Chem } & \multirow[b]{2}{*}{$\begin{array}{r}\mathrm{NMB} \\
(\%)\end{array}$} & \multirow[b]{2}{*}{$\begin{array}{r}\mathrm{NME} \\
(\%)\end{array}$} \\
\hline & & $\begin{array}{r}\text { Mean } \\
\text { Obs }\end{array}$ & $\begin{array}{r}\text { Mean } \\
\text { Sim }\end{array}$ & Corr & & & $\begin{array}{r}\text { Mean } \\
\text { Obs }\end{array}$ & $\begin{array}{r}\text { Mean } \\
\text { Sim }\end{array}$ & Corr & & \\
\hline CASTNET & $\mathrm{T} 2$ & 15.9 & 15.0 & 0.93 & -5.0 & 15.8 & 15.9 & 15.1 & 0.64 & -4.9 & 32.9 \\
\hline SEARCH & $\mathrm{T} 2$ & 19.4 & 18.4 & 0.94 & -4.3 & 12.3 & 19.4 & 18.4 & 0.65 & -5.1 & 27.6 \\
\hline CASTNET & SWDOWN & 176.1 & 214.7 & 0.91 & 21.8 & 36.2 & 176.1 & 189.2 & 0.80 & 7.4 & 50.4 \\
\hline SEARCH & SWDOWN & 217.7 & 245.0 & 0.91 & 11.5 & 31.6 & 217.7 & 211.0 & 0.78 & -3.0 & 47.2 \\
\hline CASTNET & WS10 & 2.3 & 3.0 & 0.44 & 28.1 & 66.4 & 2.3 & 3.0 & 0.17 & 27.5 & 80.7 \\
\hline SEARCH & WS10 & 2.2 & 2.4 & 0.47 & 9.6 & 50.9 & 2.2 & 2.4 & 0.23 & 8.0 & 62.3 \\
\hline NADP & Precip & 18.9 & 20.7 & 0.54 & 10.2 & 71.2 & 18.9 & 20.5 & 0.55 & 9.7 & 70.6 \\
\hline GPCC & Precip & 2.2 & 2.3 & 0.83 & 1.1 & 22.6 & 2.2 & 2.2 & 0.83 & -1.3 & 22.0 \\
\hline MODIS & $\mathrm{CF}$ & 57.6 & 60.4 & 0.82 & 6.2 & 12.7 & 57.6 & 57.8 & 0.87 & 0.3 & 8.9 \\
\hline MODIS & AOD & - & - & - & - & - & 0.10 & 0.05 & -0.09 & -46.6 & 54.4 \\
\hline MODIS & COT & - & - & - & - & - & 17.2 & 6.3 & 0.45 & -63.5 & 63.6 \\
\hline MODIS & CWP & - & - & - & - & - & 160.1 & 97.3 & 0.54 & -39.2 & 54.9 \\
\hline MODIS & QVAPOR & - & - & - & - & - & 1.04 & 1.13 & 0.96 & 9.0 & 27.7 \\
\hline MODIS & $\mathrm{CCN}$ & - & - & - & - & - & 0.33 & 0.09 & 0.60 & -73.2 & 73.2 \\
\hline TERRA & CDNC & - & - & - & - & - & 155.0 & 123.5 & 0.10 & -20.0 & 59.2 \\
\hline CASTNET & $\operatorname{Max} 1 \mathrm{~h} \mathrm{O}_{3}$ & - & - & - & - & - & 47.4 & 33.2 & 0.40 & -30.0 & 34.8 \\
\hline CASTNET & $\operatorname{Max} 8 \mathrm{~h} \mathrm{O}_{3}$ & - & - & - & - & - & 43.8 & 32.7 & 0.40 & -25.3 & 32.0 \\
\hline AQS & $\operatorname{Max} 1 \mathrm{~h} \mathrm{O}_{3}$ & - & - & - & - & - & 48.4 & 40.7 & 0.34 & -15.8 & 28.0 \\
\hline AQS & $\operatorname{Max} 8 \mathrm{~h} \mathrm{O}_{3}$ & - & - & - & - & - & 42.3 & 35.3 & 0.20 & -17.0 & 29.2 \\
\hline STN & $24 \mathrm{~h} \mathrm{PM}_{2.5}$ & - & - & - & - & - & 11.0 & 9.7 & 0.17 & -11.5 & 54.6 \\
\hline IMPROVE & $24 \mathrm{~h} \mathrm{PM}_{2.5}$ & - & - & - & - & - & 4.5 & 4.0 & 0.44 & -11.5 & 56.0 \\
\hline STN & $24 \mathrm{~h} \mathrm{SO}_{4}$ & - & - & - & - & - & 2.2 & 2.6 & 0.33 & 19.0 & 68.5 \\
\hline IMPROVE & $24 \mathrm{~h} \mathrm{SO}_{4}$ & - & - & - & - & - & 1.0 & 1.3 & 0.50 & 21.1 & 72.3 \\
\hline STN & $24 \mathrm{~h} \mathrm{NO}_{3}$ & - & - & - & - & - & 1.4 & 0.7 & 0.10 & -45.6 & 89.1 \\
\hline IMPROVE & $24 \mathrm{~h} \mathrm{NO}_{3}$ & - & - & - & - & - & 0.4 & 0.2 & 0.30 & -43.3 & 95.5 \\
\hline STN & $24 \mathrm{~h} \mathrm{NH}_{4}$ & - & - & - & - & - & 1.0 & 1.0 & 0.21 & 1.5 & 72.5 \\
\hline STN & $24 \mathrm{~h} \mathrm{EC}$ & - & - & - & - & - & 0.4 & 1.0 & 0.14 & 147.1 & 179.5 \\
\hline IMPROVE & $24 \mathrm{~h} \mathrm{EC}$ & - & - & - & - & - & 0.2 & 0.3 & 0.29 & 78.5 & 123.8 \\
\hline STN & $24 \mathrm{~h} \mathrm{TC}$ & - & - & - & - & - & 2.8 & 2.5 & 0.10 & -11.9 & 62.0 \\
\hline IMPROVE & $24 \mathrm{~h} \mathrm{OC}$ & - & - & - & - & - & 0.9 & 0.6 & 0.18 & -29.6 & 74.2 \\
\hline IMPROVE & $24 \mathrm{~h} \mathrm{TC}$ & - & - & - & - & - & 1.0 & 0.9 & 0.21 & -11.8 & 72.8 \\
\hline Pasadena, $\mathrm{CA}^{2}$ & SOA & - & - & - & - & - & 0.63 & 0.16 & 0.1 & -75.3 & 78.3 \\
\hline Bakersfield, $\mathrm{CA}^{2}$ & SOA & - & - & - & - & - & 0.51 & 0.23 & 0.3 & -55.3 & 65.9 \\
\hline
\end{tabular}

${ }^{1}$ Units are as follows: SWDOWN $\left(\mathrm{W} \mathrm{m}^{-2}\right), \mathrm{GLW}\left(\mathrm{W} \mathrm{m}^{-2}\right), \mathrm{OLR}\left(\mathrm{W} \mathrm{m}^{-2}\right), \mathrm{T} 2\left({ }^{\circ} \mathrm{C}\right), \mathrm{RH} 2(\%), \mathrm{WS} 10\left(\mathrm{~m} \mathrm{~s}^{-1}\right), \mathrm{WD} 10\left({ }^{\circ}\right), \operatorname{Precip}(\mathrm{mm}), \mathrm{CWP}\left(\mathrm{g} \mathrm{m}^{-2}\right)$, QVAPOR $(\mathrm{cm}), \mathrm{CCN}\left(10^{9} \mathrm{~cm}^{-2}\right), \mathrm{CDNC}\left(\mathrm{cm}^{-2}\right), \mathrm{O}_{3}(\mathrm{ppb}), \mathrm{PM}$ and PM species $\left(\mu \mathrm{g} \mathrm{m}^{-3}\right)$. CASTNET - the Clean Air Status and Trends Network; AQS - the Aerometric Information Retrieval System/Air Quality System; SEARCH - the Southeastern Aerosol Research and Characterization; GPCC - the Global Precipitation Climatology Centre; MODIS - the Moderate Resolution Imaging Spectroradiometer; IMPROVE - the Interagency Monitoring of Protected Visual Environments; STN - the Speciated Trends Network. Note that IMPROVE did not contain NH4+ data for 2010. "-" indicates that the results of those variables are not available from the WRF-only simulation. ${ }^{2}$ The observed SOA data are taken from Lewandowski et al. (2013).

shows normalized mean bias (NMB) vs. normalized mean error (NME) plots for several meteorological variables by seasons against several observational networks for 2006 and 2010. In general, there are a number of similar trends in terms of meteorological model performances in 2006 and 2010. These systematic biases give insight into the consistency of the model performance in reproducing observations. First, for T2, the model tends to perform the worst among all seasons for JFD for both 2006 and 2010 and, with the exception of JFD 2006 against CASTNET and JJA 2010 against CASTNET, the T2 performance falls within an NMB of 0 to $\sim-10 \%$, which means a slight underprediction of $\mathrm{T} 2$ for all other seasons for both years. Second, for SWDOWN (downward shortwave radiation), the evaluation against CASTNET gives overpredictions for all seasons for both years, with the largest overprediction in JFD, and the model performs well against SEARCH with very small positive and negative NMBs for all seasons both years. Third, WS10 is overpredicted for all seasons and for both years against CASTNET and SEARCH. Overall, the correlation coefficients for 2006 are better than those for 2010, as the correlations between mean observed and simulated values for all meteorological 
2006
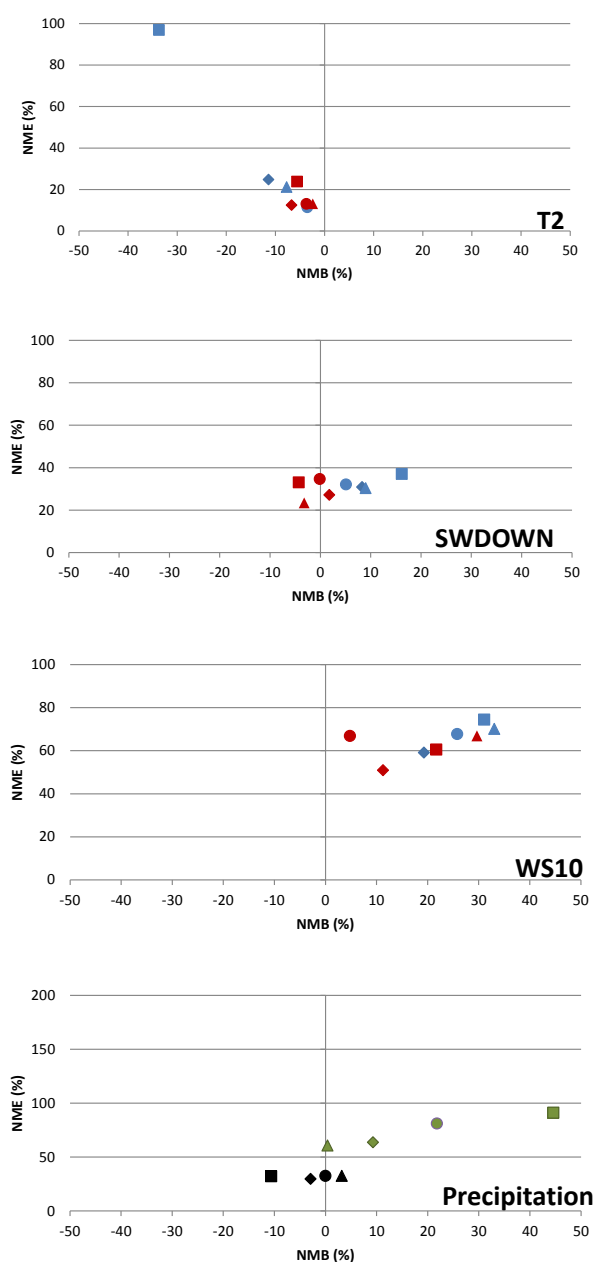

2010
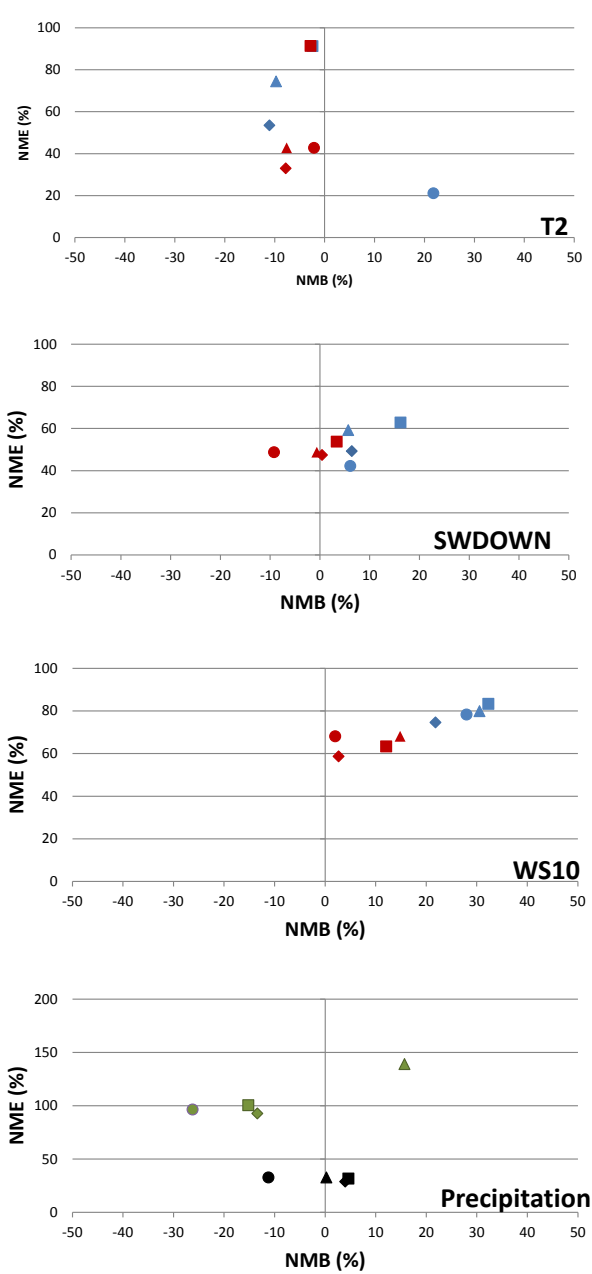

Figure 1. Comparison of seasonal plots of NMB vs. NME of various meteorological variables for 2006 (left column) and 2010 (right column) - T2 (temperature at $2 \mathrm{~m}$ ), SWDOWN (downward shortwave radiation), WS10 (wind speed at $10 \mathrm{~m}$ ) and precipitation where the shapes represent different seasons (diamond - MAM, circle - JJA, triangle - SON and square - JFD) and the different colors represent different observational data (red - SEARCH, blue - CASTNET, green - NADP, black - GPCC).

variables are higher for 2006 compared to 2010. However, the biases are smaller for temperatures at $2 \mathrm{~m}$ (T2) (against CASTNET), SWDOWN, wind speed at $10 \mathrm{~m}$ (WS10), precipitation (Precip) (against NADP), cloud fraction (CF), and cloud droplet number concentrations (CDNC) for 2010 compared to 2006. T2 is underpredicted against CASTNET and SEARCH for both 2006 and 2010. The seasonal mean NMBs for both 2006 and 2010 (except for JFD 2006) are < 15\%, with annual mean NMBs of -7.7 and $-4.9 \%$, respectively. With the exception of JFD 2006 against CASTNET, T2 predictions in the other seasons in 2006 for both CASTNET and SEARCH have lower NMEs $(<25 \%)$ for 2006 . All the seasons in 2010 have an NME of $>25 \%$ for T2 predictions. For SWDOWN, for both 2006 and 2010, seasonal NMBs range from -10 to $20 \%$ with annual mean NMBs of 21.3 and $7.4 \%$, respectively, against CASTNET and 3.0 and $12.4 \%$, respectively, against SEARCH; however the seasonal and annual mean NMEs in 2006 are $<40 \%$ while those in 2010 range from 40 to $65 \%$. Although SWDOWN is overpredicted on an annual basis, T2 is underpredicted in all seasons in 2006 and all seasons except for JJA in 2010, as T2 is diagnosed from the skin temperature, which depends on not only SWDOWN but also other variables such as soil properties. The NCEP, Oregon State University, Air Force, National Weather Service Office of Hydrology (NOAH) land surface model used in this case calculates the heat fluxes and skin temperatures based on SWDOWN, the land-use type, and soil properties including soil texture, soil moisture, soil conductivity and thermal diffusivity which vary for different soil types (Chen, 2007). Pleim and Gilliam (2009) also reported the cold bias for T2 especially for the winter of 2006 for their WRF simulations, which was reduced by implementing deep 
soil temperature and moisture nudging in their work. In this study, however, deep soil data nudging was not used. Annual mean WS10 is overpredicted for both 2006 and 2010 (with NMBs of $17.4-27.4 \%$ in 2006 and $8-27.5 \%$ in 2010) but to a much smaller extent compared to previous studies. This is because the Mass and Owens (2010) surface roughness parameterization is used in this work in WRF and WRF/Chem, which helps reduce typical overpredictions in WS10 overall in both years. SWDOWN tends to be overpredicted for CASTNET due to underpredictions in cloud variables which will be covered in Sect. 3.4. CF is the only meteorological variable with a better performance in terms of all three measures, including Corr, NMB, and NME in 2010 than in 2006 against MODIS. The better performance in CF in 2010 may help reduce annual mean NMBs in CDNC, SWDOWN, and T2 in 2010, although their annual mean NMEs increase and annual mean Corr values decrease.

For precipitation, the model performs consistently well against GPCC for both years with seasonal NMBs within -11 and $-12 \%$, and annual NMBs of 0.3 and $1.3 \%$, respectively, for 2006 and 2010. The evaluation against NADP shows larger differences with NMBs of 22.2 and $2.5 \%$ and Corr values of 0.43 and 0.1 for 2006 and 2010, respectively. As compared to other meteorological variables such as T2, SWDOWN, and WS10, the meteorological performance for precipitation does not follow a clear trend for all seasons or years against NADP and GPCC. For example, precipitation in JJA is underpredicted against NADP and GPCC for 2010 but this is not the case for 2006. In general, the reported biases in precipitation simulated by WRF from literature are significant. For example, Wang and Kotamarthi (2014) studied the precipitation behavior in WRF and showed that even with nudging, the precipitation biases remained up to a root mean square error (RMSE) of $62.5 \%$ due to inherent weaknesses in the microphysics and cumulus parameterization schemes. Similarly, WRF/Chem gives large seasonal mean biases (up to $44 \%$ in 2006 and up to $-26 \%$ in 2010) for simulated precipitation for most seasons in 2006 or 2010, although the annual mean biases are small to moderate (with NMBs of -2.2 to $-1.3 \%$ against GPCC and of 9.7-17.6\% against NADP in both years). Yahya et al. (2014) compared and evaluated the full-year WRF and WRF/Chem 2006 simulations with the same physical configurations to analyze the effects of feedbacks from chemistry to meteorology. The results for 2006 show that for the evaluation of SWDOWN, T2, and WS10 against CASTNET and SEARCH, the Corr is almost identical for both WRF/Chem and WRF simulations. For evaluation of precipitation against NADP, WRF has a higher Corr compared to WRF/Chem. Unlike 2006, the 2010 WRF-only simulation has higher Corr values for all meteorological variables compared to the $2010 \mathrm{WRF} / \mathrm{Chem}$ simulation except for Precip against GPCC and CF against MODIS. This means that the emissions and chemistry-meteorological feedbacks play an important role in influencing model performance. Section 4.4 will explore this in further detail. Another obvious difference is that the NMBs for the meteorological variables for 2010 are smaller compared to 2006 for all the variables except for Precip against GPCC, while the NMEs are larger for 2010 compared to 2006 for all variables except for Precip against GPCC. A smaller overall averaged NMB but a larger NME may indicate compensation of over- and underpredictions leading to a small bias, but the magnitude of the differences are reflected in the NME values.

The same model physics and dynamics options are used for both years. In addition to different emissions, there are characteristic climate differences between the 2 years that lead to lower Corr values and larger NMEs for most meteorological fields in 2010 compared to 2006 for both WRF and WRF/Chem simulations. The year 2010 is reported to be the warmest year globally since 1895 according the National Climactic Data Center (NCDC) (http://www.ncdc.noaa.gov/ cag/). Even though 2010 has high temperatures compared to previous years, a trend analysis of extreme heat events (EHE) from 1930 to 2010 showed that in 2010 there were more than 35 extreme minimum heat events (where temperatures are extremely low) over the southeastern US compared to about $\sim 10$ events in 2006. In fact, the number of extreme minimum heat events is the highest overall for CONUS in 2010 compared to all the other years from 1930 onwards (Oswald and Rood, 2014). The Intergovernmental Panel for Climate Change (IPCC) reported that, since 1950, weather events have become more extreme likely due to climate change (IPCC, 2012). Grundstein and Dowd (2011) stated that, on average, by 2010 there would be 12 more days with extreme apparent temperatures than those in 1949. These studies imply that increased temperatures change the weather in unexpected ways with uncertainties in the state of science $(\mathrm{Hu}-$ ber and Gulledge, 2011), including models. These high and low temperatures could contribute to the compensation of over- and underpredictions leading to smaller NMBs in general for 2010. To better simulate model extreme heat events, Meir et al. (2013) suggested using a higher spatial resolution with a grid size of $12 \mathrm{~km}$ or smaller, better sea surface temperature estimates, and enhanced urbanization parameterization. Gao et al. (2012) reported better results in reproducing extreme weather events with WRF over the eastern US at a $4 \mathrm{~km} \times 4 \mathrm{~km}$ resolution. In this study, although the urban canopy model is used for both WRF and WRF/Chem simulations, a $36 \mathrm{~km} \times 36 \mathrm{~km}$ grid resolution might not be sufficient to reproduce the extreme temperature events (highs and lows) in 2010.

As shown in Fig. S4, the spatial distribution of MB (mean bias) values for T2 for JFD 2010 by WRF/Chem show very large negative MBs over the southeastern US compared to JFD 2006. T2 is also generally underpredicted over the southeastern US in both years but with larger negative biases in 2010 than those in 2006. T2 biases also seem to be more extreme for JFD 2010 compared to JFD 2006, with dark red and dark blue colors for the MB markers, indicating large positive and large negative biases, respectively. This could 

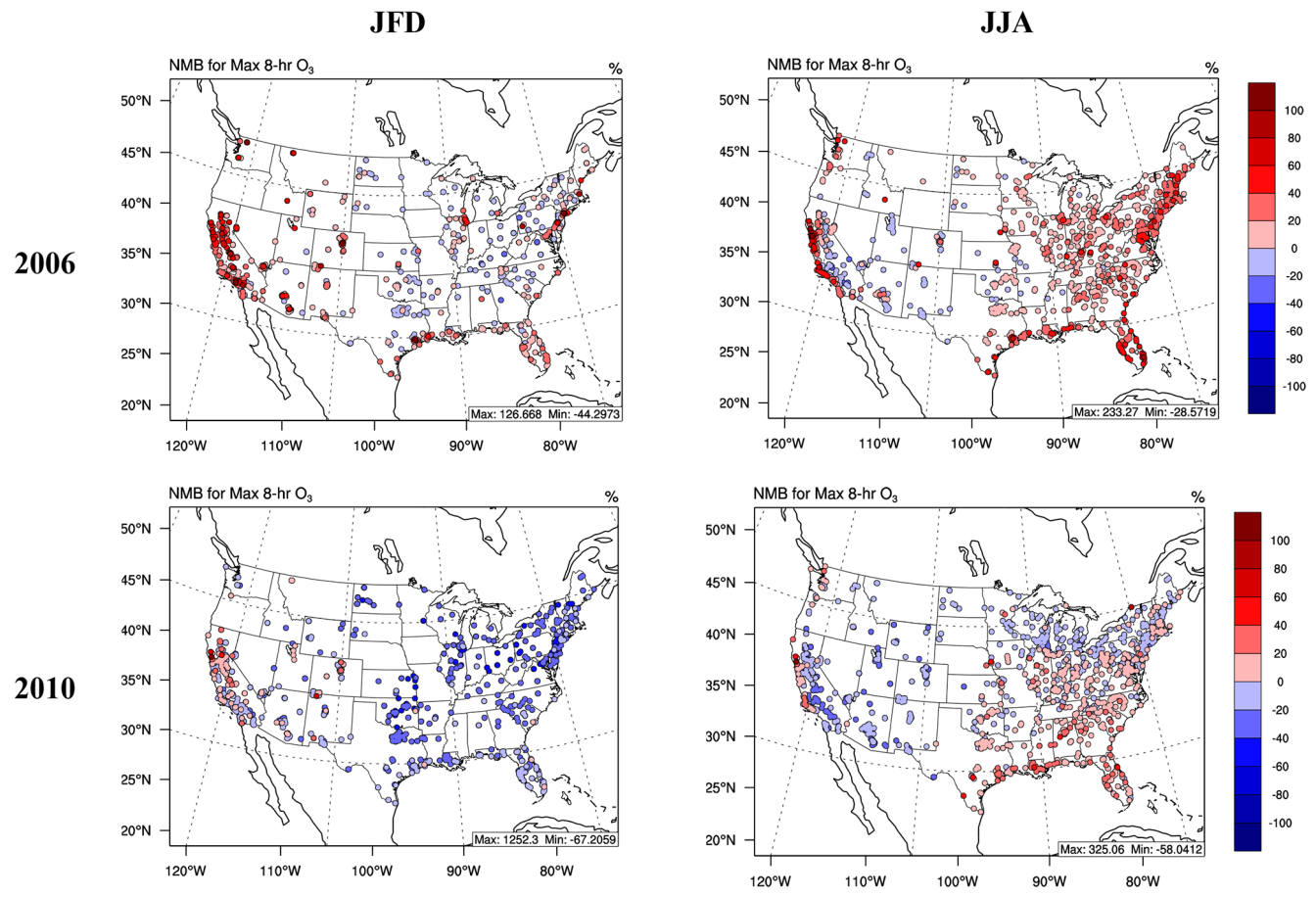

Figure 2. Spatial distribution of NMB plots for JFD and JJA 2006 and 2010 for maximum $8 \mathrm{~h} \mathrm{O}_{3}$ concentrations, based on evaluation against CASTNET, AQS and SEARCH.
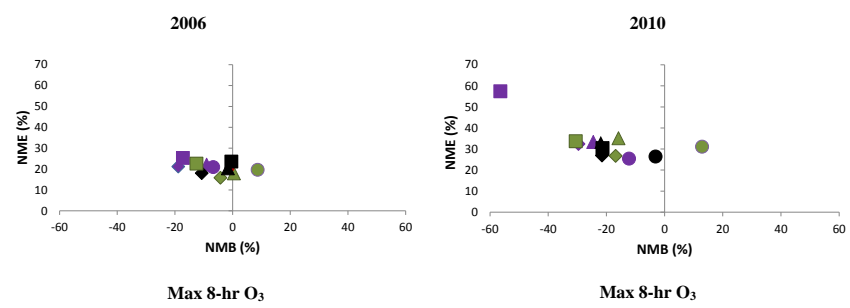

Figure 3. Comparison of seasonal plots of NMB vs. NME for maximum $8 \mathrm{~h} \mathrm{O}_{3}$ concentrations where the different shapes represent different seasons (diamond - MAM, circle - JJA, triangle - SON and square - JFD) and the different colors represent different observational data (purple - CASTNET, black - AQS and green SEARCH).

explain the poorer correlation for $\mathrm{T} 2$ in 2010 compared to 2006 as shown in Table 1. On the other hand, the performances of T2 for JJA 2010 and 2006 are very similar, with MBs of $\sim-0.1$ to $0.1^{\circ} \mathrm{C}$ in the eastern US, large negative MBs at the sites in Montana and Colorado, and a large positive $\mathrm{MB}$ at the site in Wyoming.

\subsection{Differences in chemical predictions for 2006 and 2010}

The chemical performance between 2006 and 2010 is more variable compared to the meteorological performance of surface variables. The lower Corr for 2010 compared to 2006 for meteorological variables has a large influence on the model performance for 2010. As shown in Table 1, all the chemical variables for all networks have lower a Corr in 2010 compared to 2006. As shown in Figs. 2 and 3, the maximum $8 \mathrm{~h} \mathrm{O}_{3}$ concentrations are underpredicted to a larger extent in 2010 compared to 2006 , dominating the $\mathrm{O}_{3}$ annual performance in 2010. These results are consistent with the results of Hogrefe et al. (2014). The large underpredictions of maximum $8 \mathrm{~h} \mathrm{O}_{3}$ in JFD 2010 over the southeastern US are attributed to larger cold biases in T2 shown in Fig. S4 and reduced $\mathrm{NO}_{x}$ and $\mathrm{VOC}$ emissions in 2010 relative to their levels in 2006. While reduced $\mathrm{NO}_{x}$ levels can result in an increase in nighttime $\mathrm{O}_{3}$ concentrations due to reduced $\mathrm{NO}_{x}$ titration of $\mathrm{O}_{3}$, the impact of reduced $\mathrm{NO}_{x}$ titration on the maximum $8 \mathrm{~h} \mathrm{O}_{3}$ is small. As shown in Fig. S4, the temperature biases for both years are relatively similar. Over the northeastern US, the $\mathrm{T} 2$ bias is generally less than $-0.1{ }^{\circ} \mathrm{C}$ for JJA in both years. However, as shown in Fig. 2, $\mathrm{O}_{3}$ concentrations over the northeastern US in JJA 2010 have negative biases whereas those over the northeastern US in JJA 2006 have positive biases. In this case, emissions might play a significant role in the underprediction of $\mathrm{O}_{3}$ concentrations over the northeastern US in JJA 2010. Hourly average surface $\mathrm{NO}_{x}$ emissions decrease significantly over the northeastern US in JJA from 2006 to 2010. As shown in Fig. 3, 2006 model performance for $\mathrm{O}_{3}$ is generally good for all seasons and all networks. 
JFD
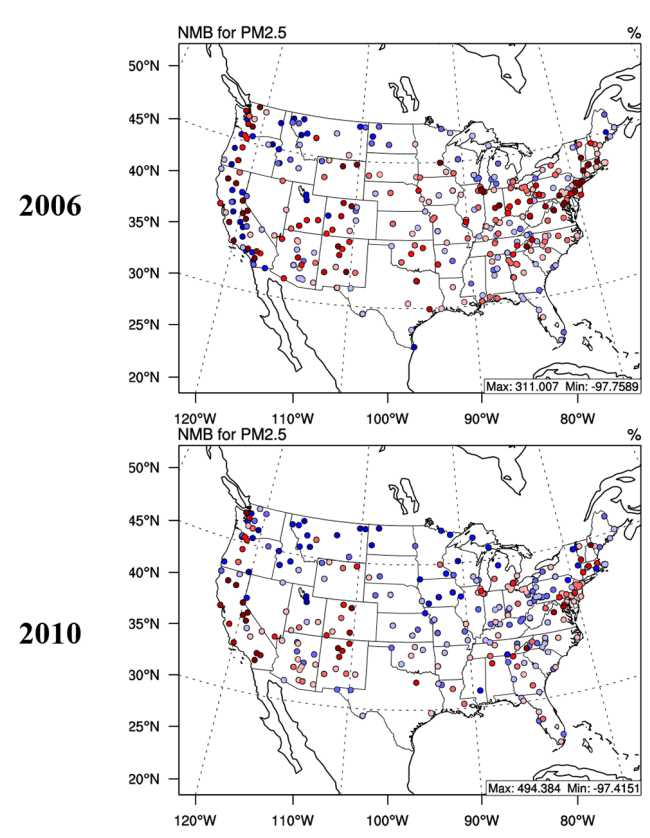

JJA
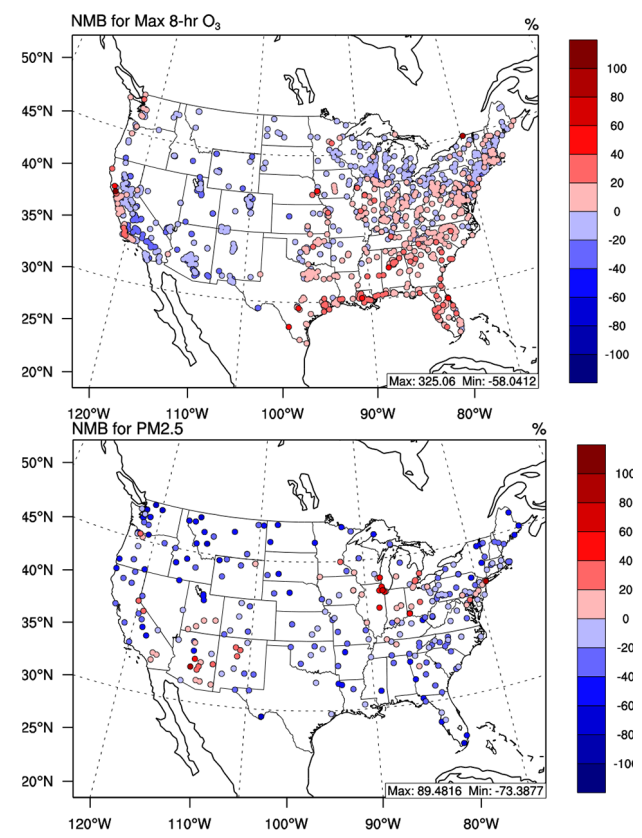

Figure 4. Diurnal variation of T2 (top row) and hourly $\mathrm{O}_{3}$ concentrations (bottom row) against CASTNET for JJA 2006 and 2010.

According to Table 1 and Fig. 1, WRF/Chem predicts SWDOWN to a lower extent in 2010 compared to 2006 against CASTNET. Khiem et al. (2010) reported that during the summer, a large percentage of the variations in peak $\mathrm{O}_{3}$ concentrations during the summer can be attributed to changes in seasonally averaged daily maximum temperature and seasonally averaged WS10. Simulated WS10 is lower for 2010 compared to 2006 in general; therefore, WS10 does not seem to contribute to reduced $\mathrm{O}_{3}$ concentrations (through dispersion, increased dry deposition) in 2010. Figure 4 shows diurnal variations of observed and simulated WRF/Chem T2 and $\mathrm{O}_{3}$ concentrations from CASTNET in JJA 2006 and 2010. The diurnal averaging provides insight into whether the underpredictions of $\mathrm{O}_{3}$ mixing ratios are a systematic bias during the daytime or nighttime or both. The diurnally averaged observed temperatures show a similar trend in JJA 2006 to 2010 against T2 measurements from CASTNET. This shows that the model is able to reproduce T2 for different years. The temperature trends also correlate strongly with the $\mathrm{O}_{3}$ trends. At night, where the model has a cold bias, $\mathrm{O}_{3}$ concentrations are underpredicted to a larger extent. The $\mathrm{O}_{3}$ concentrations show a larger underprediction for JJA 2010 compared to JJA 2006. The underpredictions in $\mathrm{O}_{3}$ in both 2006 and 2010 can be explained by several reasons. For example, Im et al. (2014) showed that the MACC (Monitoring Atmospheric Composition and Climate) model underpredicts $\mathrm{O}_{3}$ mixing ratios, particularly in winter and spring during both day and night and in summer and fall during nighttime. As indicated by Wang et al. (2014) and Makar et al. (2014), the inclusion of aerosol indirect effects also tends to reduce $\mathrm{O}_{3}$ mixing ratios, comparing to the models that simulate aerosol direct effect only or do not simulate aerosol direct and indirect effects (i.e., offline-coupled models).

Figure 5 shows the spatial distribution of NMBs for $\mathrm{PM}_{2.5}$ concentrations for JFD and JJA 2006 and 2010 against IMPROVE, STN, and SEARCH. Overall, JJA 2006 and JJA 2010 have similar spatial distribution patterns of NMBs for all sites over CONUS except for several sites in the northwestern US where $\mathrm{PM}_{2.5}$ concentrations are underpredicted for JJA 2010 but overpredicted for JJA 2006. However, many sites have positive NMBs over the eastern and central US for JFD 2006, whereas more sites have negative NMBs over the eastern and central US for JFD 2010. Statistics from Yahya et al. (2014) and Table 1 show that, in general, the simulated concentrations of $\mathrm{PM}_{2.5}$ and all $\mathrm{PM}_{2.5}$ species decrease from 2006 to 2010; however, the Corr values for $\mathrm{PM}_{2.5}$ and $\mathrm{PM}_{2.5}$ species become worse in 2010 compared to 2006. As shown in Fig. 6, $\mathrm{PM}_{2.5}$ concentrations for 2006 can be overpredicted or underpredicted, depending on seasons and networks, with an equal distribution of positive and negative NMBs. However for 2010, $\mathrm{PM}_{2.5}$ concentrations tend to be underpredicted for all seasons and for all networks except for JFD against SEARCH. As shown in Fig. 7, NMBs for $\mathrm{PM}_{2.5}$ species for 2006 at individual monitoring sites range from -40 to $60 \%$, while those for 2010 range from -80 to $80 \%$. The markers are more spread out covering a wider range of NMBs and NMEs for 2010 with more extremes as compared to the markers for 2006 clustered around the zero NMB line. 
JFD

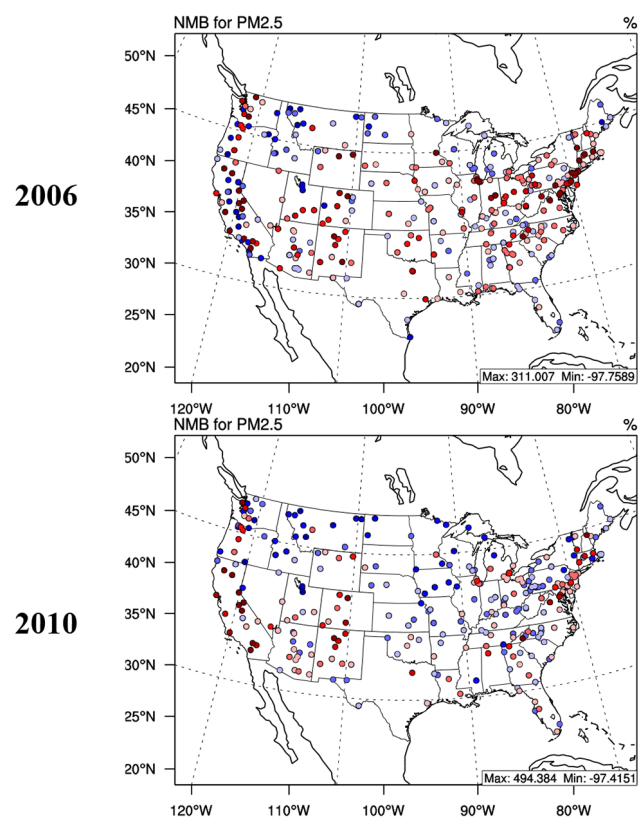

JJA
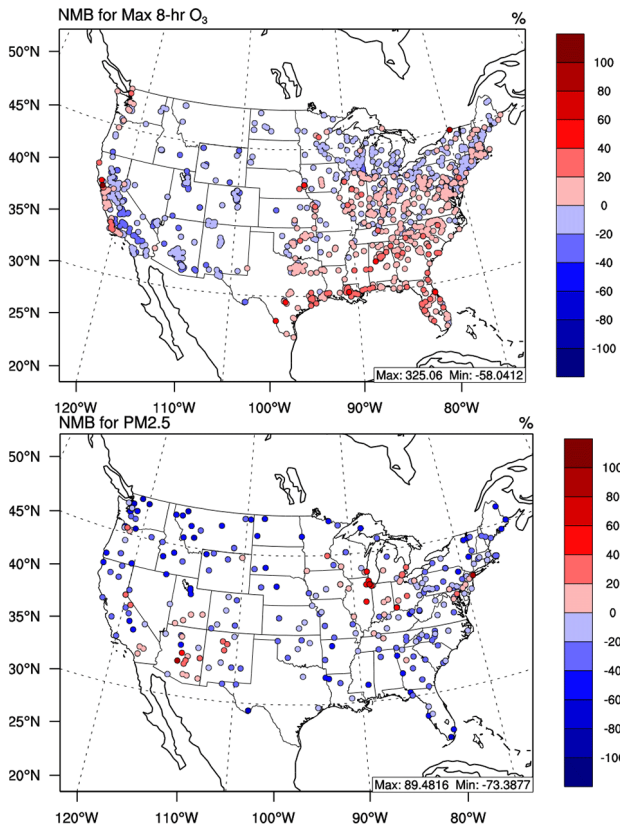

Figure 5. Spatial Distribution of NMB plots for JFD and JJA 2006 and 2010 for average $24 \mathrm{~h}^{\mathrm{PM}_{2.5}}$ concentrations based on evaluation against the IMPROVE, STN and SEARCH sites.

NMEs for $\mathrm{PM}_{2.5}$ species in 2006 remain below $100 \%$. $\mathrm{NO}_{3}^{-}$ concentrations are slightly underpredicted in 2006 against all networks; however, $\mathrm{NO}_{3}^{-}$levels in 2010 are largely underpredicted, likely due to the large decrease in $\mathrm{NO}_{x}$ emissions from 2006 to 2010 and the increase in T2. The NMBs for IMPROVE and SEARCH OC (organic carbon) remain low from 2006 to 2010; however, the NMEs increase significantly. For TC (total carbon) against IMPROVE, the NMBs and NMEs in 2010 are larger in magnitude in 2010 than those in 2006. $\mathrm{SO}_{4}^{2-}$ has lower NMBs but higher NMEs for all networks in 2010 compared to 2006. EC concentrations are generally overpredicted in 2006 for all networks but underpredicted against SEARCH and largely overpredicted against IMPROVE in 2010. $\mathrm{NH}_{4}^{+}$also has higher NMEs in 2010 compared to 2006. Overall, the evaluation in 2010 shows larger NMEs and weaker correlations for all $\mathrm{PM}_{2.5}$ species compared to 2006.

Figure 8 shows the time series plots for $24 \mathrm{~h}$ average concentrations of $\mathrm{PM}_{2.5}, \mathrm{SO}_{4}^{2-}$ and $\mathrm{NO}_{3}^{-}$against $\mathrm{STN}$ for 2006 and 2010. In 2006, the daily-average PM data were collected on a daily basis in 2006 but every 3 days in 2010. The model is able to predict most of the observed peaks and troughs for 2006 even though the observed and simulated magnitudes are significantly different for several days. For 2010, the model does not show large spikes and can reproduce the magnitudes well, although it does not predict the peaks and troughs as well as 2006 for some months (e.g., JanuaryMarch and July-September for $\mathrm{PM}_{2.5}$ ). This could be at-
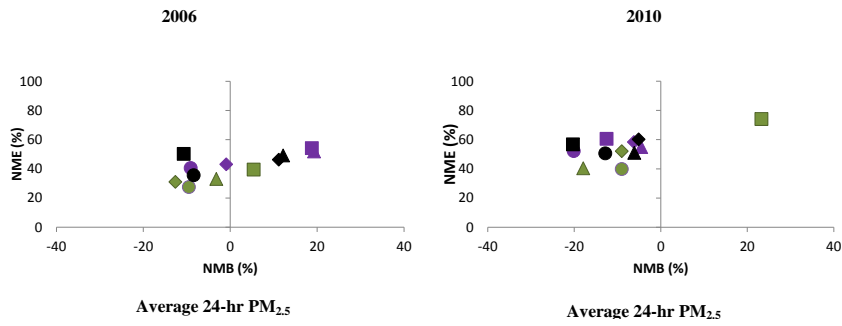

Figure 6. Comparison of seasonal plots of NMB vs. NME for average $24 \mathrm{~h} \mathrm{PM}_{2.5}$ concentrations where the different shapes represent different seasons (diamond - MAM, circle - JJA, triangle SON and square - JFD) and the different colors represent different observational data (purple - IMPROVE, black - STN and green SEARCH).

tributed in part to the weaker correlations of meteorological variables in 2010 compared to 2006. For example, inaccurate predictions of WS10 can influence the transport and dry deposition of aerosols. An overprediction of precipitation increases the wet deposition of aerosols. Poor predictions of T2 can influence the planetary boundary layer height (PBLH) and both can also affect the distribution of aerosol concentrations. $\mathrm{NO}_{3}^{-}$concentrations for the winter months are moderately underpredicted in 2006 but largely underpredicted in 2010 , likely due to the underpredictions in nitrogen dioxide $\left(\mathrm{NO}_{2}\right)$ concentrations (Yahya et al., 2014). Section 4 will dis- 

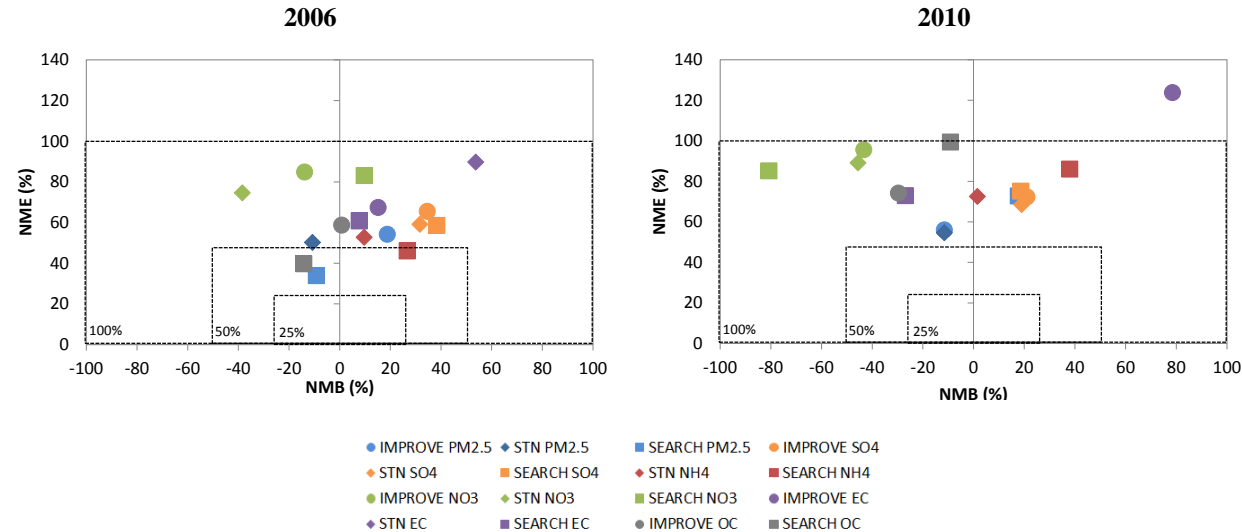

Figure 7. Plots of annual statistics (NMB vs. NME) for average $24 \mathrm{~h} \mathrm{PM}_{2.5}$ concentrations and $\mathrm{PM}_{2.5}$ species against different observational networks.
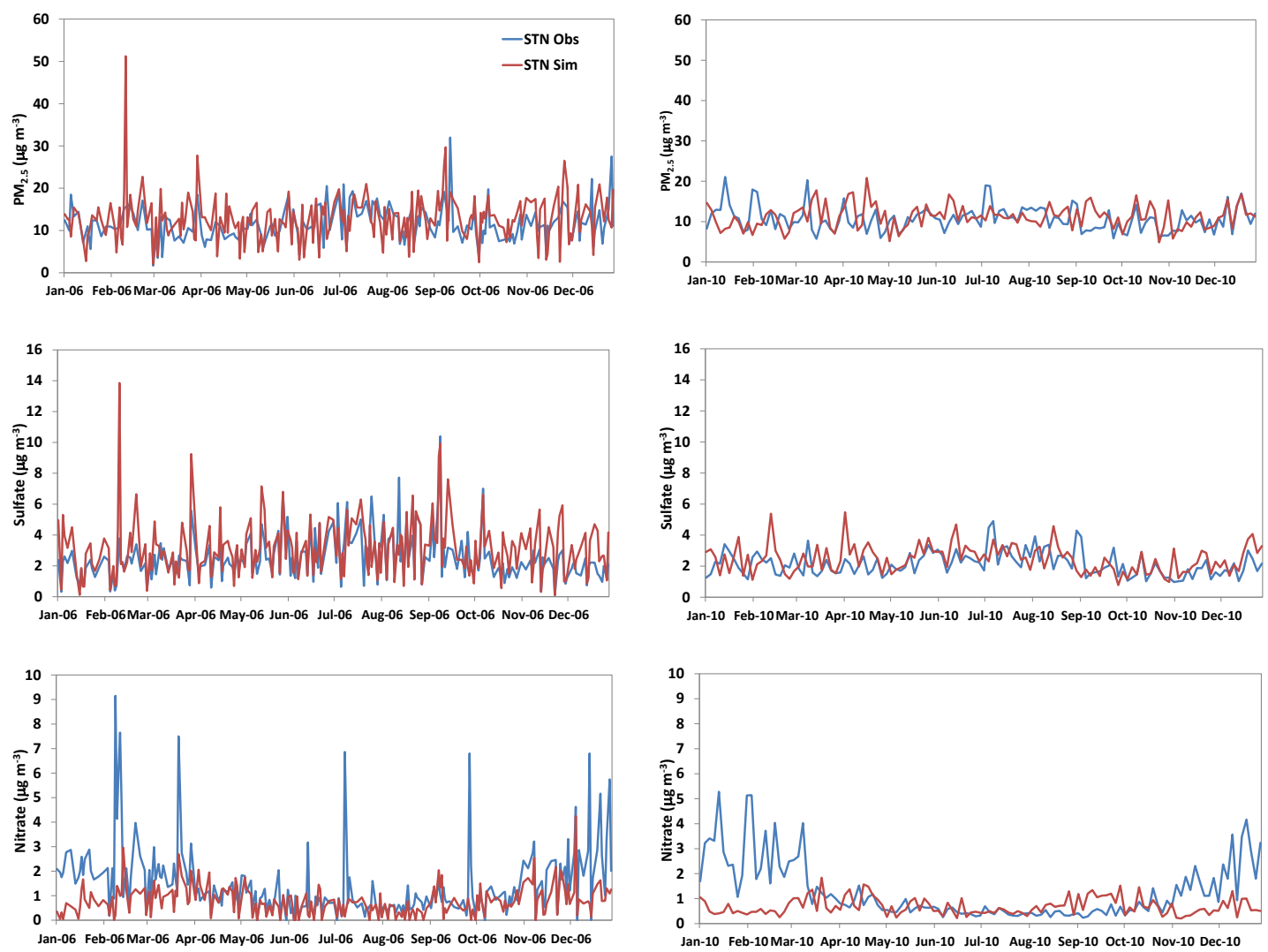

Figure 8. Time series of Obs vs. Sim $\mathrm{PM}_{2.5}, \mathrm{SO}_{4}$ and $\mathrm{NO}_{3}$ concentrations against STN for 2006 and 2010.

cuss in further detail the role of emissions, meteorology and chemical ICONs/BCONs on $\mathrm{O}_{3}$ and $\mathrm{PM}_{2.5}$ concentrations.

\subsection{SOA evaluation for 2006 and 2010}

The VBS framework in WRF/Chem of Ahmadov et al. (2012) provides a more realistic treatment of SOA compared to previous SOA treatments such as the 2product model by Odum et al. (1996) used in the Sec- ondary Organic Aerosol Model (SORGAM) of Schell et al. (2001). Wang et al. (2014) evaluated SOA and OC concentrations simulated from WRF/Chem-CB05-MADE/VBS and WRF/Chem-CB05-MADE/SORGAM over NA for July 2006 against field campaign data from Offenberg et al. (2011) at the Research Triangle Park (RTP), North Carolina (NC), for July 2006. They showed significant improvement in simulating SOA and total organic aerosol (TOA) by 

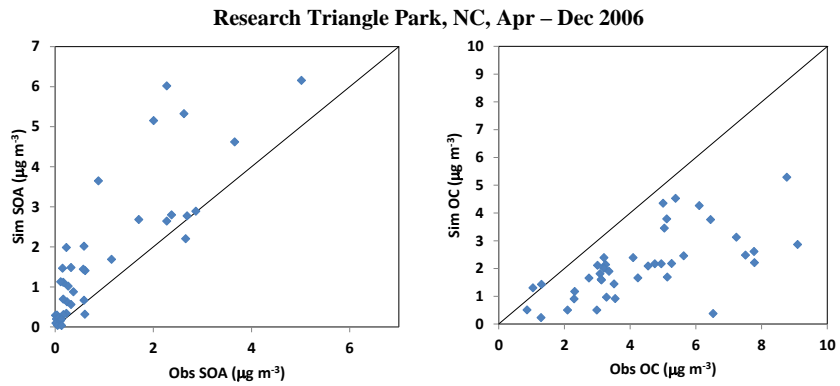

Pasadena, CA, May - June 2010 (this study)
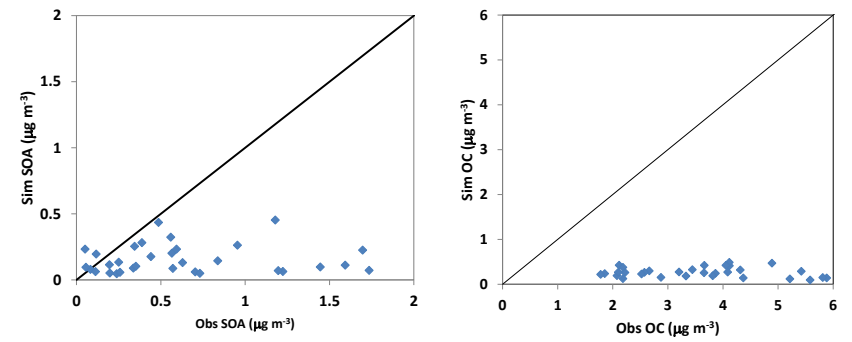

Bakersfield, CA, May - June 2010 (this study)
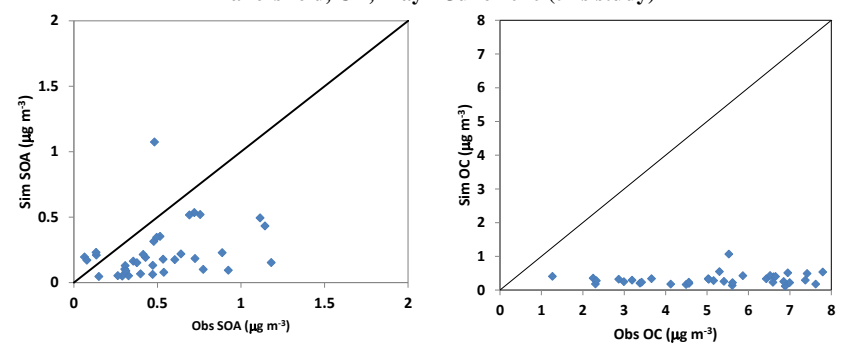

Figure 9. Scatter plots of SOA (left column) and OC (right column) concentrations at various sites.

VBS than by SORGAM. In this study, SOA and OC predictions are evaluated against available field campaign data at RTP, NC, in the eastern US from Offenberg et al. (2011) for 2006 only, and Pasadena and Bakersfield, CA, in the western US from Lewandowski et al. (2013) for 2010 only (note that no observations are available at the same sites for both years). The RTP site is located in a semi-rural area. Pasadena, CA, is located about $11 \mathrm{mi}$. from downtown Los Angeles (LA), and Bakersfield, CA, is located about $\sim 100 \mathrm{mi}$. from downtown LA. Both sites are classified as urban/industrial sites. OC concentrations were measured using an automated, semicontinuous elemental carbon-organic carbon (EC-OC) instrument. The observed SOA masses were determined from organic tracers extracted from filter samples (Lewandowski et al., 2013). The simulated OC concentration is calculated by summing up SOA and POA, and dividing the TOA by 1.4 (Aitken et al., 2008).

As shown in Figs. 9 and S5, the model overpredicts SOA but underpredicts OC at RTP in 2006 because (1) the SOA formed from alkanes and alkenes is excluded in the observations from RTP but simulated in WRF/Chem, and (2) WRF/Chem may have overestimated the aging rate co- efficient for both anthropogenic and biogenic surrogate VOC precursors (Wang et al., 2014). The SOA overprediction due to those reasons compensates the underprediction in SOA due to omission of SOA from POA, leading to a net SOA overprediction at RTP in 2006. By contrast, the VBS underpredicts SOA in 2010 with NMBs of -55.3 and $-75.3 \%$ at Bakersfield and Pasadena, respectively, which is mainly due to the omission of SOA formation from POA in the current VBS-SOA module in this version of WRF/Chem. As shown in Fig. S6, SOA to OC ratios at RTP in 2006 are in the range of $50-80 \%$, whereas they are $<20 \%$ at Bakersfield, CA, and $<40 \%$ Pasadena, CA, in 2010. This indicates that neglecting SOA formation from POA would have a much larger impact on SOA predictions at the two CA sites in 2010 than at RTP in 2006, due to the dominancy of POA in TOA at the two CA sites. As shown in Fig. 9, the model underpredicts OC at RTP in 2006 and significantly underpredicts $O C$ at the two sites in CA in 2010. The differences in OC performance in both years are caused by different locations (i.e., RTP in 2006 and the two CA sites in 2010) that have different ratios of POC to OC as mentioned previously. OC performance thus largely depends on SOA performance at RTP but on POA performance at the two sites in CA. This is why the OC performance remains poor despite a relatively good performance in SOA at the two sites in CA. A poorer OC performance over the two CA sites in 2010 may also indicate potentially large underestimation of POA emissions over the western US.

\subsection{Differences in aerosol-cloud predictions for 2006 and 2010}

Figure 10 shows NMBs vs. NMEs of several aerosol and cloud variables for JFD and JJA in 2006 and 2010 against satellite data. Table 1 lists the corresponding annual performance statistics for 2010. The model is able to reproduce generally similar performances against observations for most of the aerosol-cloud variables for both 2006 and 2010 as the trends of NMBs and NMEs are quite similar for both seasons in both years. For JJA 2006 and 2010, all cloud variables are underpredicted with approximately the same magnitudes of NMBs and NMEs. For JJA, the model performs better for 2010 for CF, aerosol optical depth (AOD), and cloud optical thickness (COT) in terms of seasonal mean spatial distribution. For JFD, the model performs better for CF and cloud water path (CWP) in 2010. In terms of annual statistics, compared to 2006, 2010 has lower NMBs for CF and COT but larger biases in AOD, CWP, and cloud condensation nuclei $(\mathrm{CCN})$, leading to large differences in aerosol-radiation and cloud-radiation feedbacks, which in turn affect the performance of meteorological and chemical predictions. Despite the differences in model performance of meteorological and chemical variables in 2010 compared to 2006, performance of cloud variables do not vary significantly. One possible reason is because the evaluation of aerosol-cloud variables is based on monthly values that are averaged out on a seasonal 

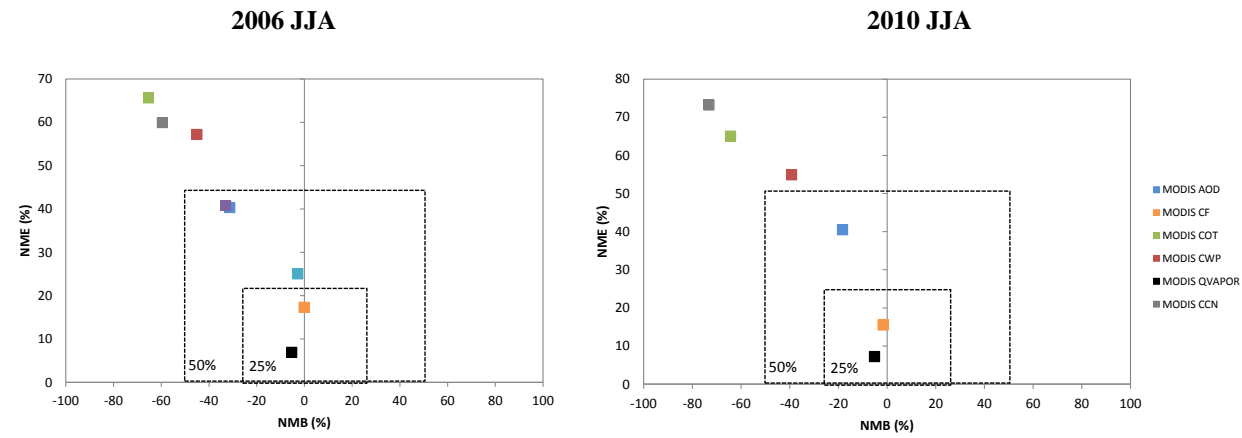

2006 JFD

2010 JFD
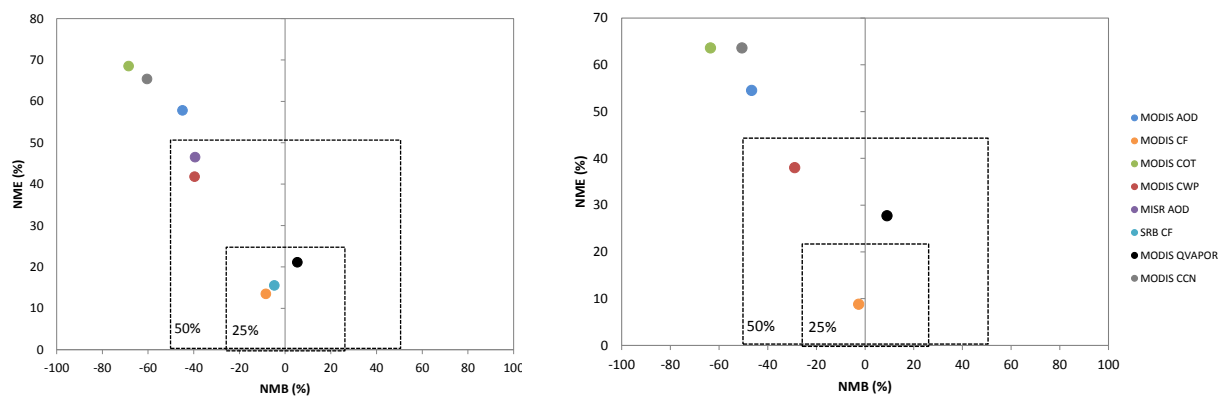

Figure 10. Comparison of soccer plots for JFD and JJA 2006 and 2010 evaluation of aerosol and cloud variables. Multiangle Imaging SpectroRadiometer (MISR) AOD, and Surface Radiation Budget (SRB) CF Obs data were not available for 2010.

basis. The meteorological and chemical variables shown earlier are evaluated based on site-specific, and hourly, daily, or weekly data.

\subsection{Differences in observed and simulated trends between 2010 and 2006}

Table 2 shows the percentage changes in observed and WRFonly and WRF/Chem-simulated variables between 2010 and 2006. Overall, the model is able to predict the trends in all major meteorological, chemical, and aerosol-cloudradiation variables between 2006 and 2010 with a few exceptions (e.g., WS10 against CASTNET, Precip, CF, maximum $8 \mathrm{~h} \mathrm{O} 3$ against CASTNET, and $24 \mathrm{~h} \mathrm{EC}$ against IMPROVE). The trends in simulated T2, SWDOWN, and SEARCH WS10 are generally consistent with the observed trends from 2006 to 2010. Both observed and simulated temperatures at $2 \mathrm{~m}$ (T2) at the CASTNET sites increase by $\sim 4{ }^{\circ} \mathrm{C}$ or $\sim 35-40 \%$ from 2006 to 2010. For SWDOWN, both observed and simulated values at the CASTNET and SEARCH sites increase by $\sim 1-3 \%$ and by $\sim 5-7 \%$, respectively, from 2006 to 2010. The observed WS10 remains relatively constant at CASTNET in both years. The simulated WS10 by WRF also shows no change but that by WRF/Chem shows a small decrease (by $-8.3 \%$ ) for the CASTNET sites. Comparing to a SEARCH-observed change of $\sim-4 \%$ in WS10, WRF and WRF/Chem predict a larger decrease from 2006 to $2010(\sim-12$ to $-13 \%)$. The trends for Precip and CF for simulated variables are not consistent with observed trends from 2006 to 2010. Observed NADP Precip increased slightly from 2006 to 2010 by $\sim 7 \%$; however, both simulated WRF and WRF/Chem show a small decrease from 2006 to 2010. Observed mean GPCC Precip remained relatively constant from 2006 to 2010; however, WRF only shows a slight increase $(\sim 4 \%)$ while WRF/Chem shows a larger decrease $(-12 \%)$ from 2006 to 2010 . MODIS CF decreased by $-0.2 \%$ from 2006 to 2010 whereas both WRF and WRF/Chem show small increases of 3-4\% from 2006 to 2010. Apart from the large biases in the evaluation of precipitation, the decrease in precipitation is likely due to the smaller decrease in SWDOWN for WRF/Chem compared to observations between 2006 and 2010. This would result in less convective precipitation during the summer but increased CF for 2010. In addition, $\mathrm{PM}_{2.5}$ is underpredicted but agrees better with observed $\mathrm{PM}_{2.5}$ in 2010 than in 2006 . Underpredicted $\mathrm{PM}_{2.5}$ concentrations will also affect the formation of clouds and precipitation via various direct and indirect effects.

The simulated decreasing trends between 2006 and 2010 are overall consistent with the observed decreasing trend between 2006 and 2010 for all species except for maximum $8 \mathrm{~h}$ $\mathrm{O}_{3}$ concentrations from CASTNET and EC from IMPROVE. CASTNET maximum $1 \mathrm{~h}$ and $8 \mathrm{~h} \mathrm{O}_{3}$ concentrations change very little from 2006 to 2010 whereas WRF/Chem shows a moderate decrease of 14-15\%. The large decrease in simulated $\mathrm{O}_{3}$ mixing ratios in 2010 can be attributed to a large 
Table 2. Percentage changes in observed and simulated variables between 2010 and 2006 .

\begin{tabular}{|c|c|c|c|c|}
\hline Network or site name & Variable & Obs & WRF & WRF/Chem \\
\hline CASTNET & $\mathrm{T} 2$ & 35.7 & 38.6 & 40.1 \\
\hline SEARCH & $\mathrm{T} 2$ & 1.3 & 0.0 & 0.5 \\
\hline CASTNET & SWDOWN & 2.1 & 2.6 & 1.4 \\
\hline SEARCH & SWDOWN & 7.3 & 7.4 & 5.2 \\
\hline CASTNET & WS10 & 0.0 & 0.0 & -8.3 \\
\hline SEARCH & WS10 & -4.3 & -13.4 & -12.4 \\
\hline NADP & Precip & 6.7 & -4.3 & -1.5 \\
\hline GPCC & Precip & 0.0 & 4.5 & -12.0 \\
\hline MODIS & $\mathrm{CF}$ & -0.2 & 3.7 & 3.0 \\
\hline MODIS & AOD & -28.6 & - & -44.4 \\
\hline MODIS & COT & 4.2 & - & 6.8 \\
\hline MODIS & CWP & -10.2 & - & -11.1 \\
\hline MODIS & QVAPOR & -47.5 & - & -42.1 \\
\hline MODIS & $\mathrm{CCN}$ & -2.9 & - & -30.8 \\
\hline CASTNET & $\operatorname{Max} 1 \mathrm{~h} \mathrm{O}_{3}$ & -0.5 & - & -15.0 \\
\hline CASTNET & $\operatorname{Max} 8 \mathrm{~h} \mathrm{O}_{3}$ & 0.6 & - & -13.9 \\
\hline AQS & $\operatorname{Max} 1 \mathrm{~h} \mathrm{O}_{3}$ & -3.9 & - & -14.6 \\
\hline AQS & $\operatorname{Max} 8 \mathrm{~h} \mathrm{O}_{3}$ & -4.9 & - & -17.4 \\
\hline STN & $24 \mathrm{~h} \mathrm{PM}_{2.5}$ & -9.9 & - & -20.8 \\
\hline IMPROVE & $24 \mathrm{~h} \mathrm{PM}_{2.5}$ & -16.1 & - & -27.0 \\
\hline STN & $24 \mathrm{~h} \mathrm{SO}_{4}$ & -25.8 & - & -33.3 \\
\hline IMPROVE & $24 \mathrm{~h} \mathrm{SO}_{4}$ & -23.7 & - & -26.3 \\
\hline STN & $24 \mathrm{~h} \mathrm{NO}_{3}$ & -11.3 & - & -27.8 \\
\hline IMPROVE & $24 \mathrm{~h} \mathrm{NO}_{3}$ & -20.0 & - & -53.5 \\
\hline STN & $24 \mathrm{~h} \mathrm{NH}_{4}$ & -25.3 & - & -31.9 \\
\hline STN & $24 \mathrm{~h} \mathrm{EC}$ & -39.5 & - & -1.6 \\
\hline IMPROVE & $24 \mathrm{~h} \mathrm{EC}$ & -21.6 & - & 2.4 \\
\hline STN & $24 \mathrm{~h} \mathrm{TC}$ & -38.1 & - & -24.2 \\
\hline IMPROVE & $24 \mathrm{~h} \mathrm{OC}$ & -17.3 & - & -45.5 \\
\hline IMPROVE & $24 \mathrm{~h} \mathrm{TC}$ & -25.5 & - & -35.7 \\
\hline
\end{tabular}

${ }^{1}$ The percentages are calculated according to this formula: [(2010 value -2006 value $) / 2006$ value $\times 100 \%$. CASTNET - the Clean Air Status and Trends Network; AQS - the Aerometric Information Retrieval System/Air Quality System; SEARCH - the Southeastern Aerosol Research and Characterization; GPCC - the Global Precipitation Climatology Centre; MODIS - the Moderate Resolution Imaging Spectroradiometer; IMPROVE - the Interagency Monitoring of Protected Visual Environments; STN - the Speciated Trends Network. Note that IMPROVE did not contain $\mathrm{NH} 4+$ data for 2010 "." indicates that the results of those varibles are not avalable from the WRF-only simultion.

decrease in $\mathrm{O}_{3}$ mixing ratios from the ICONs and BCONs (Stoeckenius et al., 2015). The IMPROVE-observed EC concentrations decreased by $\sim 22 \%$ from 2006 to 2010; however, WRF/Chem shows a small increase (by $\sim 2 \%$ ). For $\mathrm{PM}_{2.5}$ concentrations, the simulated decrease from 2006 to 2010 by WRF/Chem is larger than the observed decrease for both STN and IMPROVE. Similar steeper decreases by WRF/Chem also occur for $\mathrm{SO}_{4}^{2-}$ against STN, $\mathrm{NO}_{3}^{-}$against IMPROVE, TC against STN, and OC against IMPROVE likely due to the influence of ICONs/BCONs and emissions.

\section{Responses of 2010 predictions to changes in emissions and meteorology}

The changes in emissions, boundary conditions, and meteorology between 2010 and 2006 lead to changes in simulated air quality and the chemistry-meteorology feedbacks, which in turn change meteorological and air quality predictions during the next time step.

\subsection{Air quality predictions}

Simulated air quality responds nonlinearly to the changes in emissions. Figures 11, and S7-S9 show the seasonal changes between 2010 and 2006 in ambient mixing ratios of gases $\left(\mathrm{SO}_{2}, \mathrm{NO}_{2}, \mathrm{NH}_{3}, \mathrm{O}_{3}\right.$, and hydroxyl - $\left.\mathrm{OH}\right)$ and concentrations of PM species $\left(\mathrm{SO}_{4}^{2-}, \mathrm{NO}_{3}^{-}, \mathrm{NH}_{4}^{+}\right.$, organic matter or OM, EC, POA, anthropogenic SOA or ASOA, biogenic SOA or BSOA, and $\mathrm{PM}_{2.5}$ ). $\mathrm{SO}_{2}$ and $\mathrm{NO}_{2}$ concentrations tend to decrease for all seasons at most locations over CONUS due to the decrease in their emissions. The increases in $\mathrm{NO}_{2}$ concentrations over urban areas in the eastern US in March, April, May (MAM) in 2010 relative to 2006 could be due to a few reasons including decreased photolytic conversion from $\mathrm{NO}_{2}$ to $\mathrm{NO}$ due to a decrease in SWDOWN and less $\mathrm{NO}_{2}$ conversion to nitric acid $\left(\mathrm{HNO}_{3}\right)$ due to decreased $\mathrm{OH}$ concentrations. The $\mathrm{NO}_{2}$ hot spots also correlate to the decrease in hourly $\mathrm{O}_{3}$ concentrations in urban areas. This could indicate an increased titration of nighttime $\mathrm{O}_{3}$ by NO. This is an important result for policy implications, as reducing $\mathrm{NO}_{x}$ emissions may reduce $\mathrm{NO}_{2}$ concentrations overall for CONUS, but may not reduce $\mathrm{NO}_{2}$ concentrations in several areas, especially in urban areas due to a combination of titration and complex interplay with local meteorology. $\mathrm{NH}_{3}$ mixing ratios generally decrease in the US, except over the eastern US in MAM and September, October, and November (SON), where there are increases. $\mathrm{NH}_{3}$ emissions decrease, however, over the eastern US in all seasons. The increase in $\mathrm{NH}_{3}$ concentrations in MAM and SON could be attributed to a number of reasons including less $\mathrm{NH}_{3}$ conversion to $\mathrm{NH}_{4}^{+}$ to neutralize $\mathrm{SO}_{4}^{2-}$ and $\mathrm{NO}_{3}^{-}$and less dispersion of $\mathrm{NH}_{3}$ concentrations due to decreased wind speeds over the eastern and southeastern US in MAM and SON, respectively, in 2010 compared to 2006. In JJA and SON, high OM concentrations in Canada are attributed to the enhanced impacts of BCONs by increasingly convergent flow in this region. OM is made up of both POA and SOA. An increase in VOC emissions in the eastern US in MAM and SON leads to increases in OM concentrations. Decreases in VOC emissions in the western U.S. for all seasons lead to decreases in OM concentrations. The OM concentrations in some areas, however, do not follow a linear relationship with VOC emissions, such as for the southeastern US in JJA, where VOC emissions increase from 2006 to 2010 but OM concentrations decrease. A decrease in POA concentrations must dominate the overall decrease in OM concentrations, even under increased temperatures and biogenic VOC emissions in this area. $\mathrm{PM}_{2.5}$ concentrations decrease for all seasons and most regions of the CONUS, which is attributed mainly to decreases in precursor gases, especially the inorganic precursors $\mathrm{SO}_{2}$ and $\mathrm{NO}_{x}$ in the eastern US. Increased $\mathrm{PM}_{2.5}$ concentrations in JFD and MAM in the Midwest are due to surface temperature decreases, which are dominating in this region (Stoeckenius et al., 2015). This in turn leads to increased particle nitrate concentrations (Campbell et al., 2014). 

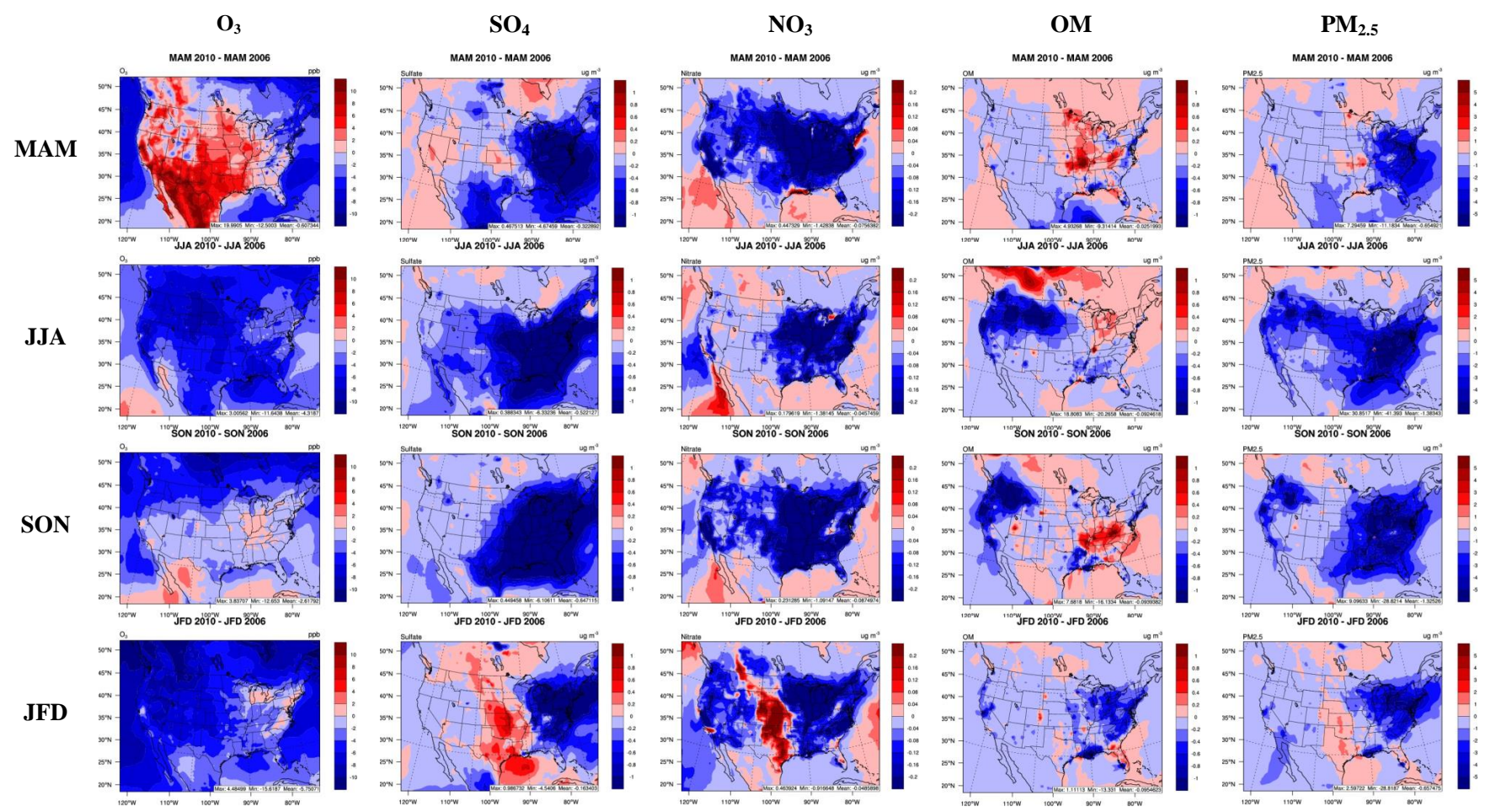

Figure 11. Changes in hourly average surface concentrations of $\mathrm{O}_{3}$ and $\mathrm{PM}$ species from 2010 to 2006 (2010-2006).

\subsection{Meteorological predictions}

Figure S10 compares the seasonal changes between 2010 and 2006 in several meteorological variables that affect air pollution including SWDOWN, T2, WS10, PBLH, and Precip simulated by WRF-only simulations without considering chemistry feedbacks. Large changes occur in those variables between the 2 years, e.g., $10-50 \mathrm{~W} \mathrm{~m}^{-2}$ increases in SWDOWN in the western and midwest US in JJA, generally warmer in JJA and SON over most areas but cooler by $3-$ $10^{\circ} \mathrm{C}$ in the eastern US in JFD, and with reduced Precip in the eastern or southeastern US in JJA and SON but increased Precip in the northwestern US in MAM and JJA and in the western US in JFD. ICONs and BCONs for skin temperatures shown in Fig. S3 greatly influence T2 shown in Fig. S10 for JFD and JJA.

Figures 12 and S11 show the seasonal changes between 2010 and 2006 in several meteorological and cloud variables (SWDOWN, T2, WS10, Precip, PBLH, AOD, COT, CF, CWP, and CDNC) for WRF/Chem, which accounts for meteorology-chemistry feedbacks. The relationships between various meteorological variables have been discussed in Yahya et al. (2014). Comparing to the differences in predictions of SWDOWN, T2, WS10, Precip, and PBLH between 2010 and 2006 WRF-only simulations shown in Fig. S10 and WRF/Chem simulations shown in Figs. 12 and S11, the differences in those meteorological variables do not vary significantly in terms of trends of average sea- sonal spatial distributions between 2010 and 2006 WRF simulations and between 2010 and $2006 \mathrm{WRF} / \mathrm{Chem}$ simulations. However, there are differences in magnitudes, especially for SWDOWN. SWDOWN is affected most by the addition of chemistry in WRF/Chem as compared to WRF, especially for JFD through indirect feedback of clouds on radiation. As shown in Fig. 12, the decrease in SWDOWN from 2006 to 2010 is larger over the north-central and northwestern US and the increase in SWDOWN is smaller over the northeastern and southwestern US for MAM by WRF/Chem compared to MAM by WRF. For SON, the increase in SWDOWN from 2006 to 2010 simulated by WRF/Chem is larger over the eastern US than that by WRF. The differences between WRF and WRF/Chem are the largest for SWDOWN over the northeastern US in JFD with an increase in SWDOWN simulated by WRF but a decrease simulated by WRF/Chem from 2006 to 2010. The differences in SWDOWN are likely due to the differences in CF between the two sets of simulation pairs, as the spatial distribution for $\mathrm{CF}$ is consistent with that of SWDOWN. As expected, there are slight differences between T2 and PBLH between WRF and WRF/Chem (2010-2006) due to changes in radiation. There are also small differences between precipitation between WRF and WRF/Chem. The aerosol-cloudradiation feedbacks due to the differences between WRF and WRF/Chem for 2010 will be discussed in Sect. 4.3.

The increase in SWDOWN from 2006 to 2010 does not necessarily translate to an increase in T2. However, in gen- 
SWDOWN

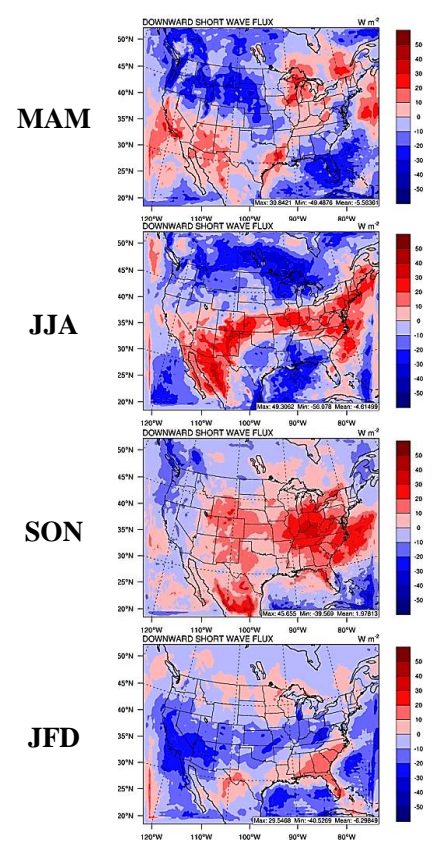

AOD

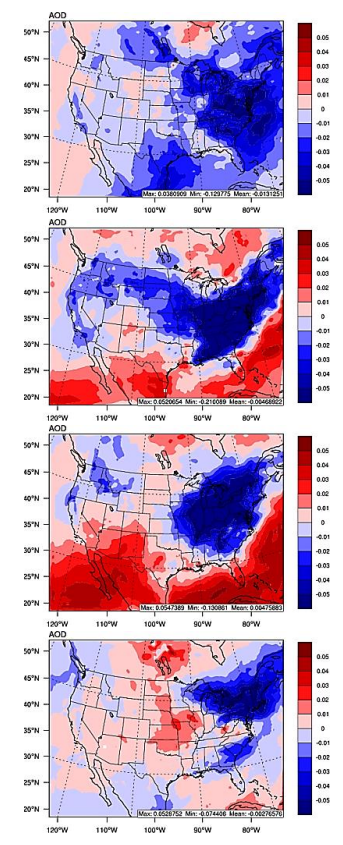

COT

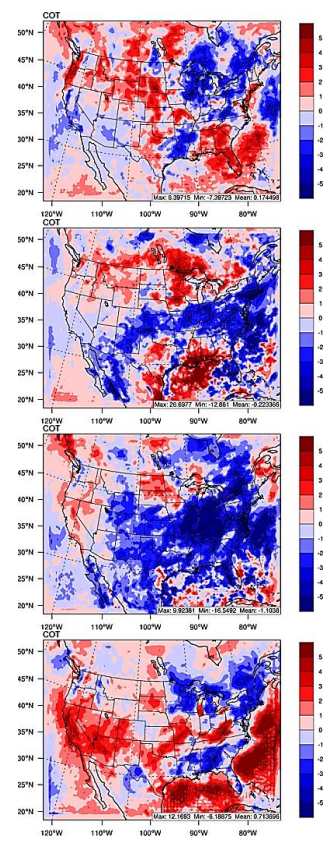

CF

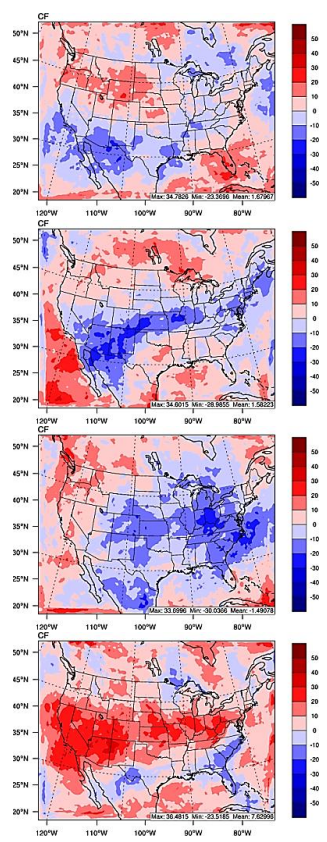

CDNC

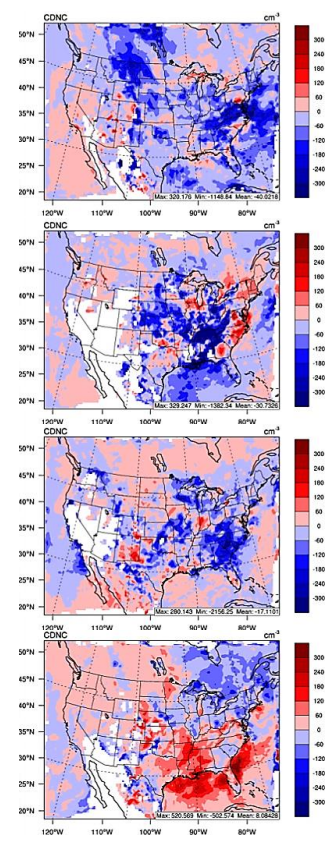

Figure 12. Changes in hourly average predictions of aerosol-cloud variables at the surface from WRF/Chem simulations from 2010 to 2006 (2010-2006).

eral, increases in SWDOWN lead to increases in $\mathrm{T} 2$, as shown in SON in Fig. 12, where SWDOWN generally increases over most of the continental US, T2 also increases over most of CONUS. In general, the largest differences in T2 between 2006 and 2010 occur in SON (increase) and JFD (decrease). The decrease in T2 in JFD in the north-central US and parts of Canada is significant as it results in a decrease in WS10 and PBLH. For JJA, there is an obvious pattern between SWDOWN and Precip, with an increase in SWDOWN corresponding to a decrease in Precip and vice versa. According to the IPCC (2007), in the warm seasons over land, strong negative correlations dominate as increased sunshine results in less evaporative cooling. Figure S12 compares wind vectors superposed with T2 in 2006 and 2010 from WRF/Chem and shows the largest differences are in JJA.

As expected, the spatial pattern of SWDOWN changes is anti-correlated with CF changes for all seasons between 2006 and 2010; however, the changes in the spatial pattern of CF do not correlate with changes in CDNC. CF in each grid cell is set to either 0 (no clouds) or to 1 (cloudy) if the total cloud water + ice mixing ratio $>1 \times 10^{-6} \mathrm{~kg} \mathrm{~kg}^{-1}$ (Wu and Zhang, 2005). In this study, the monthly CF is then normalized over the total number of time steps and vertical layers, giving a value of $\mathrm{CF}$ between 0 and 1 in each grid cell. In contrast, the calculations of CDNC in the model depend on the supersaturation, aerosol concentrations, aerosol hygroscopicity and updraft velocity (Abdul-Razzak and Ghan, 2004). The changes in CF are controlled by large-scale state variables including temperature and relative humidity, while
CDNC depends on more complex changes in microphysical variables. The dominant CDNC decrease in MAM, JJA, and $\mathrm{SON}$, is due to lower $\mathrm{PM}_{2.5}$ concentrations, which in turn lower the effective number of cloud condensation nuclei. However, an exception occurs in the southeastern US where $\mathrm{PM}_{2.5}$ decreases but CDNC increases. This is because $\mathrm{CDNC}$ also depends on other variables including the amount of liquid water in the atmosphere. The cloud liquid water path over the southeastern US increases, which may explain the increase in CDNC. The spatial pattern for precipitation correlates to that of CF. The spatial pattern of CWP also corresponds to a certain extent with CF. PBLH increases when the ground warms up during the day and decreases when the ground cools, so PBLH might be intuitively related to SWDOWN and T2. However, this consistent trend is now obvious in the plots, because the simulated growth of the planetary boundary later (PBL) also depends on the surface sensible latent and heat fluxes and the entrainment of warmer air from the free troposphere (Chen, 2007).

\subsection{Meteorology-chemistry feedback predictions}

As shown in Table 1, similar to 2006, comparison of the performance of most meteorological variables between WRF/Chem and WRF for 2010 is improved in terms of NMBs when chemistry-meteorology feedbacks are included. This indicates the importance and benefits of inclusion of such feedbacks in online-coupled models. However, unlike 2006 for which both WRF-only and WRF/Chem sim- 
Table 3. Summary of the setup of sensitivity simulations.

\begin{tabular}{lcccc}
\hline & Run 1 & Run 2 & Run 3 & Run 4 \\
\hline Emissions & 2006 & 2010 & 2006 & 2006 \\
Meteorological & 2006 & 2010 & 2010 & 2010 \\
ICONs/BCONs & & & & \\
Chemical & 2006 & 2010 & 2010 & 2006 \\
ICONs/BCONs & & & & \\
\hline
\end{tabular}

ulations show similar values of Corr and NMEs, the 2010 WRF simulations give higher Corr and lower NME values than the $2010 \mathrm{WRF} / \mathrm{Chem}$ simulations. This indicates the impact of poorer chemical predictions on chemistrymeteorology feedbacks that can in turn affect meteorological predictions. These results indicate the need of further improvement of the online-coupled models in their representations of chemistry-meteorology feedbacks. Yahya et al. (2014) analyzed differences in meteorological performance between WRF/Chem and WRF for 2006. Figure S13 shows absolute seasonal differences between the meteorological predictions from WRF/Chem and WRF for 2010. The differences between WRF/Chem and WRF are consistent for both 2006 and 2010. SWDOWN in general is higher for WRF/Chem compared to WRF for all seasons, with larger differences over the eastern portion of the domain compared to the western portion. Other obvious similarities between 2006 and 2010 include the increase in T2 over the northern portion of the domain for MAM, SON and JFD; increase in PBLH over the ocean in the eastern part of the domain for all seasons; and increases over the ocean for CF for all seasons. The reasons for the differences between WRF/Chem and WRF in terms of meteorological variables have been discussed in Yahya et al. (2014).

\subsection{Sensitivity simulations}

The aforementioned differences in WRF/Chem predictions between 2006 and 2010 are caused by changes in emissions, meteorology, and meteorological and chemical ICONs/BCONs. Additional sensitivity simulations for the months of January and July in 2010 are carried out to estimate the individual contributions of each of those changes to the total net changes in model predictions. Table 3 summarizes the configurations of the sensitivity simulations. The 2006 baseline simulations are designated as Run 1, the 2010 baseline simulations are designated as Run 2, and the two sensitivity simulations are designated as Runs 3 and 4. Run 3 is the sensitivity simulation using 2006 emissions but keeping all other inputs (e.g., meteorology and chemical ICONs/BCONs) and model configurations the same as for Run 2. Run 4 is the sensitivity simulation using 2006 emissions and chemical ICONs/BCONs keeping all other inputs and model configurations the same as for Run 2. Figures 13 and 14 show the changes due to combined effects of emis- sions, meteorological and chemical ICONs/BCONs (Run 2 Run 1 in column 1), changes due to the changes in emissions (Run 2 - Run 3 in column 2), changes due to the changes in chemical ICONs/BCONs (Run 3 - Run 4 in column 3), and changes due to the changes in meteorology including ICONs/BCONs (Run 4 - Run 1 in column 4) for January and July, respectively. Since the impact of ICONs is only important at the beginning of the simulations whereas the impact of BCONs persists throughout the simulations, the changes due to changes in chemical BCONs will dominate over those due to changes in chemical ICONs/BCONs.

Both Figs. 13 and 14 show that the differences in the meteorology due to the impact of meteorological ICONs/BCONs generated by WRF/Chem contribute to the largest differences in T2 and SWDOWN for both months (columns 1 and 4). For comparison, the changes in emissions and chemical ICONs/BCONs lead to less significant differences in $\mathrm{T} 2$ and SWDOWN (columns 2 and 3). The overall decrease in emissions from 2006 to 2010 results in a slight increase in both T2 and SWDOWN in January (column 2 in Fig. 13), and a larger increase in SWDOWN in July (column 2 in Fig. 14) due to decreases in aerosol loading. There is a small decrease in T2 and SWDOWN in January (column 3 in Fig. 13) due to influences of chemical ICONs/BCONs used for both years, but a larger decrease occurs in SWDOWN in July (column 3 in Fig. 14). As shown in Figs. 13 and 14 (column 1), changes in $\mathrm{O}_{3}$ are influenced by all factors and the overall change of the $\mathrm{O}_{3}$ mixing ratio is a combination of changes in emissions, and meteorological and chemical ICONs/BCONs. The $\mathrm{O}_{3}$ mixing ratios are greatly increased due to the use of 2010 emissions as compared to 2006 emissions (column 2 in Fig. 13), indicating that using a different set of emissions can produce an increase of up to a domain mean of $6 \mathrm{ppb}$. Conversely, $\mathrm{O}_{3}$ mixing ratios are greatly decreased (with a reduction of a domain mean of $6 \mathrm{ppb}$ ) due to the use of the 2010 chemical ICONs/BCONs compared to the 2006 chemical ICONs/BCONs (column 3 in Fig. 13). The use of different meteorological ICONs/BCONs also results in varying degrees of changes of $\mathrm{O}_{3}$ mixing ratios domainwide as $\mathrm{O}_{3}$ mixing ratios are influenced by photolysis and other meteorological parameters including wind and PBLH (column 4 in Fig. 13). In addition, T2 and SWDOWN influence the amount of BVOC (biogenic volatile organic compound) emissions produced, which also in turn influences $\mathrm{O}_{3}$ mixing ratios. In VOC-limited urban centers over the eastern US (Campbell et al., 2014), a small increase in radiation or $\mathrm{T} 2$ will increase $\mathrm{BVOC}$ emissions, increasing $\mathrm{O}_{3}$ mixing ratios and vice versa. In July (Fig. 14), the decrease in $\mathrm{O}_{3}$ mixing ratios between 2006 and 2010 (column 1) is largely influenced by chemical ICONs/BCONs (column 3) and to a smaller extent by meteorological ICONs/BCONs (column 4). In this case, the difference in emissions (column 2) does not seem to significantly impact the changes of $\mathrm{O}_{3}$ mixing ratios between July 2006 and 2010 (column 1). For January (Fig. 13), $\mathrm{PM}_{2.5}$ concentrations decrease due to decreasing 

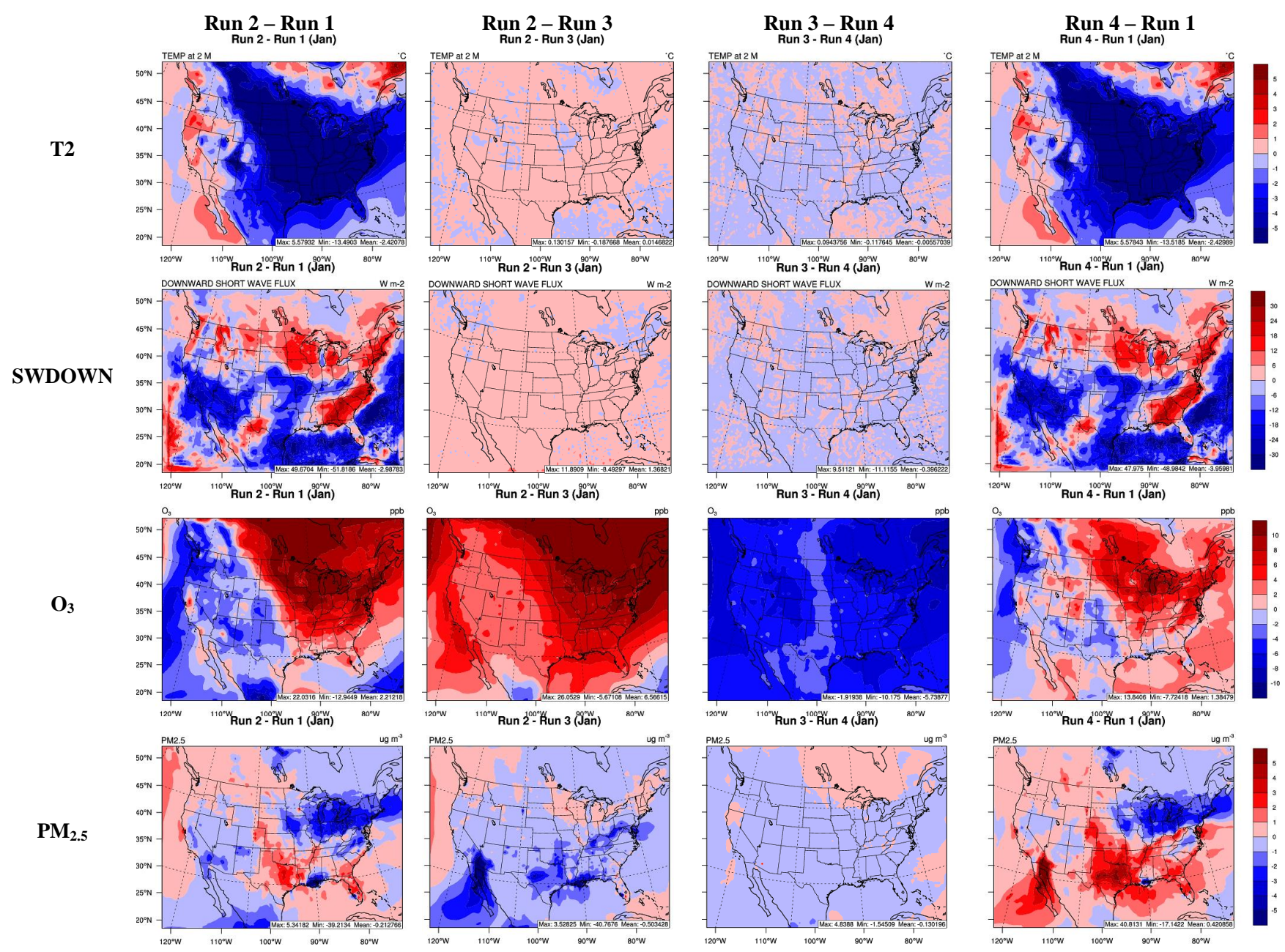

Figure 13. Spatial difference plots for January. Run 1: 2006 baseline simulations; Run 2: 2010 baseline simulations; Run 3: 2010 simulations with 2006 emissions and 2010 meteorology and chemical ICONs/BCONs; Run 4: 2010 simulations with 2006 emissions and 2006 chemical ICONs/BCONs and 2010 meteorology.

emissions and chemical ICONs/BCONs (columns 2 and 3). However, the use of 2010 meteorological ICONs/BCONs results in an increase in $\mathrm{PM}_{2.5}$ concentrations over most of the domain except for the northeastern US (with a domain mean increase of $0.4 \mu \mathrm{g} \mathrm{m}^{-3}$ ) (column 4). The overall differences (column 1 in Fig. 13) are mainly due to net effects of emissions (column 2) and changes in meteorology (column 4). For $\mathrm{PM}_{2.5}$ in July (Fig. 14), the net changes from 2006 and 2010 (column 1) are dominated entirely by changes in emissions (column 2) that increase in the southeastern and central US but decrease in the remaining domain, even though meteorological ICONs/BCONs also play a significant role (column 4).

Table S2 in the Supplement shows the statistics for the NMB, NME, and Corr for a number of variables for the sensitivity simulations for January and July. The statistics in bold highlight the sensitivity simulations with the best performance (i.e., with the lowest NMB and NME and the highest Corr). The WRF/Chem performance of T2 against CASTNET improves to a large extent in terms of NME and Corr for Runs 3 and 4 (especially for January when Run 2 performs poorly), which use 2006 emissions. This indicates that, at least for January (and to a smaller extent for July), the inaccuracy of emissions may have contributed to the worse performance of T2 against CASTNET. Run 3 also gives the best performance of T2 against CASTNET, which indicates that improvement in both emissions and chemical ICONs/BCONs can improve meteorological performances for both January and July. For SWDOWN, Runs 3 and 4 improve the performance against CASTNET for January (with lower NMB and NME and higher Corr). The cloud-aerosol variables are affected to a smaller extent by changes in emissions and chemical ICONs/BCONs compared to the meteorological variables. The performance for $\mathrm{CF}$ remains relatively the same for January and July. The performance for COT and AOD improves slightly for January with a lower 

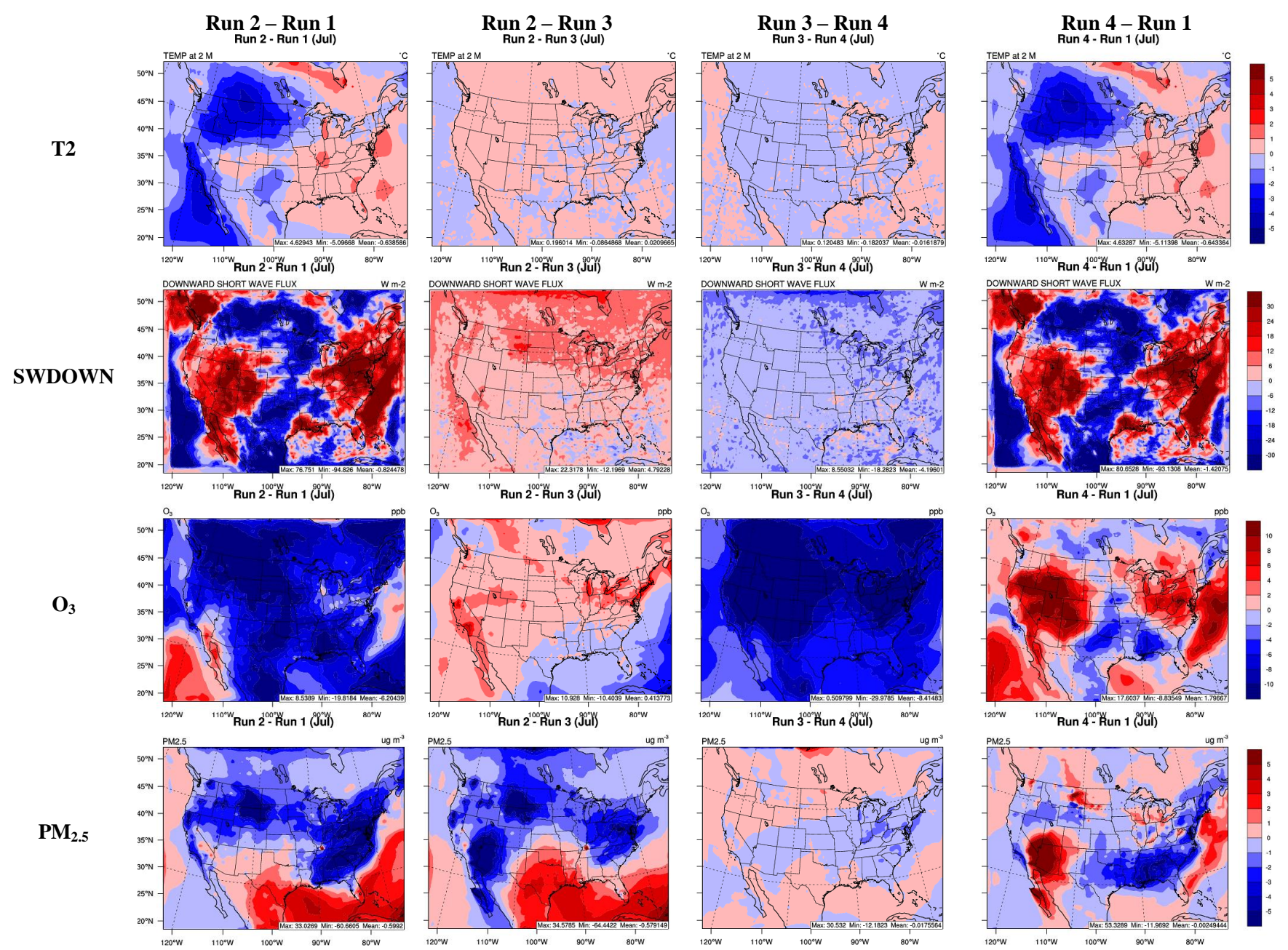

Figure 14. Spatial difference plots for July. Run 1: 2006 baseline simulations; Run 2: 2010 baseline simulations; Run 3: 2010 simulations with 2006 emissions and 2010 meteorology and chemical ICONs/BCONs; Run 4: 2010 simulations with 2006 emissions and 2006 chemical ICONs/BCONs and 2010 meteorology.

NMB and NME but becomes worse in July with a higher NMB and NME. However, as the performance of meteorological variables is significantly different, a small change in the cloud-aerosol variable can lead to a large change in meteorological variables. The performances for $\mathrm{O}_{3}$ and $\mathrm{PM}_{2.5}$ concentrations in January and July improve to a large extent when using 2006 emissions and especially when 2006 chemical ICONs/BCONs are also used. The higher emissions of $\mathrm{NO}_{x}$, VOCs, and CO for July 2006 compared to 2010 contribute to the better $\mathrm{O}_{3}$ performance, and the higher emissions of primary $\mathrm{SO}_{4}^{2-}, \mathrm{NO}_{3}^{-}, \mathrm{EC}$ and $\mathrm{OA}$ for 2006 contribute to the better $\mathrm{PM}_{2.5}$ performance for Run 3 in July. However, for January, a combination for both 2006 emissions and chemical ICONs/BCONs improves the $\mathrm{O}_{3}$ performance, while the $\mathrm{PM}_{2.5}$ performance is the best using 2010 emissions and $2010 \mathrm{ICONs} / \mathrm{BCONs}$. This indicates that inaccuracies in emissions and chemical ICONs/BCONs in 2010, especially in January, could contribute to the poor performance of WRF/Chem in 2010. These will, in turn, affect the meteorological performance to a large extent.

To evaluate if the sensitivity simulations with different meteorology, emissions, and chemical ICONs/BCONs for January and July 2010 can improve the model's capability in reproducing the trends in both meteorological and chemical variables, compared to baseline results in 2006 and 2010, the absolute and percentage differences between the monthly mean of observations of major variables in 2010 and 2006 and between simulation results from three simulation pairs Runs 2 and 1, Runs 3 and 1, and Runs 4 and 1 - are calculated and summarized in Table 4 . The differences between the 2010 baseline simulation and the 2006 baseline simulations (Run 2 - Run 1) show the impact of all the changes (including emissions, meteorology, and chemical ICONs/BCONs) in the 2010 simulation relative to the 2006 simulation on the simulated variation trends and the degree of agreement in the variation trends calculated from the two baseline sim- 
Table 4. Absolute and percentage differences between monthly mean of observed/satellite-retrieved data and sensitivity simulations.

\begin{tabular}{|c|c|c|c|c|c|}
\hline & & Obs 2010 - Obs 2006 & Run 2 - Run 1 & Run 3 - Run 1 & Run 4 - Run 1 \\
\hline \multirow{7}{*}{ Jan } & $\begin{array}{l}\text { CASTNET T2 } \\
\left(\mathrm{K} \%^{-1}\right)\end{array}$ & $-3.5 /-1.3$ & $-2.0 /-0.7$ & $-1.9 /-0.7$ & $-1.8 /-0.7$ \\
\hline & $\begin{array}{l}\text { CASTNET } \\
\text { SWDOWN } \\
\left(\mathrm{Wm}^{-2} \%^{-1}\right)\end{array}$ & $-6.2 /-7.0$ & $27.6 / 29.1$ & $-0.8 /-0.9$ & $-0.6 /-0.6$ \\
\hline & $\begin{array}{l}\text { MODIS CF } \\
\left(\%^{-1}\right)\end{array}$ & $2.7 / 4.2$ & $1.5 / 2.3$ & $1.4 / 2.1$ & $1.4 / 2.1$ \\
\hline & $\begin{array}{l}\text { MODIS COT } \\
\left(\%^{-1}\right)\end{array}$ & $-0.2 /-1.2$ & $0.2 / 2.9$ & $0.3 / 5.2$ & $0.3 / 5.5$ \\
\hline & $\begin{array}{l}\text { MODIS AOD } \\
\left(\%^{-1}\right)\end{array}$ & $-0.008 /-7.9$ & $-0.002 /-3.9$ & $0.008 / 15.3$ & $0.01 / 28.0$ \\
\hline & $\begin{array}{l}\text { CASTNET } \\
\begin{array}{ll}\operatorname{Max} 8 \mathrm{~h} & \mathrm{O}_{3} \\
\left(\mathrm{ppb} \%^{-1}\right)\end{array}\end{array}$ & $4.2 / 12.5$ & $-2.9 /-9.8$ & $-6.1 /-20.8$ & $0.7 / 2.4$ \\
\hline & $\begin{array}{l}\operatorname{STN~PM}_{2.5} \\
\left(\mu \mathrm{g} \mathrm{m}^{-3} \%^{-1}\right)\end{array}$ & $-0.2 /-1.9$ & $1.6 / 19.1$ & $1.4 / 16.5$ & $1.5 / 17.7$ \\
\hline \multirow{7}{*}{ Jul } & $\begin{array}{l}\text { CASTNET T2 } \\
\left(\mathrm{K}^{-1}\right)\end{array}$ & $0.03 / 0.0$ & $0.5 / 0.2$ & $0.5 / 0.2$ & $0.5 / 0.2$ \\
\hline & $\begin{array}{l}\text { CASTNET } \\
\text { SWDOWN } \\
\left(\mathrm{Wm}^{-2} \%^{-1}\right)\end{array}$ & $-2.8 /-1.1$ & $-7.4 /-2.6$ & $-8.9 /-3.1$ & $-5.5 /-1.9$ \\
\hline & $\begin{array}{l}\text { MODIS CF } \\
\left(\%^{-1}\right)\end{array}$ & $1.1 / 2.0$ & $-1.8 /-3.4$ & $-1.8 /-3.3$ & $-1.5 /-2.8$ \\
\hline & $\begin{array}{l}\text { MODIS COT } \\
\left(\%^{-1}\right)\end{array}$ & $-0.4 /-2.7$ & $-0.6 /-11.1$ & $-1.0 /-17.8$ & $-0.9 /-16.5$ \\
\hline & $\begin{array}{l}\text { MODIS AOD } \\
\left(\%^{-1}\right)\end{array}$ & $-0.06 /-31.0$ & $0.04 / 58.3$ & $0.06 / 79.4$ & $0.04 / 50.9$ \\
\hline & $\begin{array}{l}\text { CASTNET } \\
\begin{array}{ll}\mathrm{Max} 8 \mathrm{~h} & \mathrm{O}_{3} \\
\left(\mathrm{ppb} \%^{-1}\right) & \end{array}\end{array}$ & $-4.8 /-9.2$ & $-7.6 /-15.2$ & $-5.0 /-10.1$ & $8.6 / 17.2$ \\
\hline & $\begin{array}{l}\mathrm{STN} \mathrm{PM}_{2.5} \\
\left(\mu \mathrm{g} \mathrm{m}^{-3} \%^{-1}\right)\end{array}$ & $-0.5 /-3.7$ & $-0.5 /-4.5$ & $1.5 / 14.4$ & $1.0 / 9.8$ \\
\hline
\end{tabular}

ulations with the observed changes. Comparisons of differences between Run 3 and Run 1 (Run 3 - Run 1) with those between Run 2 and Run 1 (Run 2 - Run 1) and between Run 4 and Run 1 (Run 4 - Run 1) with those between Run 2 and Run 1 (Run 2 - Run 1) indicate the impact of changes in emissions and meteorology, respectively, on the simulated variation trends and their degree of agreement with the observed changes. As shown in Table 4, the baseline model simulations (Run 2 - Run 1) are not able to reproduce the trends in terms of either the signs or magnitude or both in the observations for some variables, including SWDOWN against CASTNET, COT against MODIS, maximum $8 \mathrm{~h} \mathrm{O}$ against CASTNET, and $\mathrm{PM}_{2.5}$ against STN in January and
CF against MODIS in July. Changing the emissions (Run 3 - Run 1) does not improve the variation trends from 2006 to 2010 with the exception of SWDOWN against CASTNET in January and maximum $8 \mathrm{~h} \mathrm{O}_{3}$ against CASTNET in July. Changing the meteorology (Run 4 - Run 1) also does not improve the variation trends to a large extent with the exception of maximum $8 \mathrm{~h} \mathrm{O}_{3}$ against CASTNET in January and SWDOWN against CASTNET in July. In fact, Run $2-$ Run 1 (which are the baseline simulations) overall performs the closest to the observed trends of major variables for January and July 2006-2010. 


\section{Summary and conclusions}

This study compares model performance in 2010 and 2006 and examines the changes in emissions, boundary conditions, and meteorology, as well as the responses of meteorology, air quality and chemistry-meteorology feedbacks to those changes collectively and individually between 2010 and 2006. In general, the emissions of most gaseous and aerosol species over CONUS decrease from 2006 to 2010 with the exception of $\mathrm{NH}_{3}$ emissions over several areas in JFD and biogenic VOCs mainly over the eastern US in JJA and SON. The increases in biogenic VOCs are caused by increases in temperatures in 2010 in the eastern US during these seasons. Overall, T2 increases from 2006 to 2010; however, the changes of T2 and other meteorological variables including SWDOWN, WS10, PBLH, and Precip vary spatially over CONUS with the largest differences for SWDOWN. The reduced emissions and changed meteorology result in decreased concentrations in general for gaseous and aerosol species except for species influenced by high BCONs, e.g., for OM concentrations over Canada in MAM and JJA. Due to increases in biogenic emissions, OM concentrations increase over the eastern US. CDNC generally decreases over the US due to the decreases in $\mathrm{PM}_{2.5}$ concentrations and $\mathrm{CCN}$ from 2006 to 2010. The spatial distributions of other meteorological and cloud variables are consistent with known processes, e.g., SWDOWN is high and precipitation is low where CF is low. There is no clear spatial correlation between $\mathrm{CF}$ and CDNC due to the differences in their inherent prognostic treatments. COT corresponds relatively well to AOD, especially for JJA in both years. CWP also corresponds well to COT. Sensitivity simulations show that the net changes in meteorological predictions in 2010 relative to 2006 are influenced mostly by changes in meteorology. Those of $\mathrm{O}_{3}$ and $\mathrm{PM}_{2.5}$ concentrations are influenced to a large extent by emissions and/or chemical ICONs/BCONs, but meteorology may also influence them to some degrees, particularly in winter.

In general, the model performs well in terms of Corr and NMEs for almost all meteorological and chemical variables in 2006 but not as well in 2010 despite lower NMBs for most variables in 2010, due mainly to inaccuracies in emission estimates and chemical BCONs and ICONs used for 2010 simulations. The model is able to reproduce the observations to a large extent for most meteorological surface variables. The model performs relatively well for $\mathrm{PM}_{2.5}$ concentrations. However, OC concentrations are significantly underpredicted against field data for 2010 in Bakersfield and Pasadena, CA, due mainly to underestimations in emissions of POA that contribute to most $\mathrm{OC}$ and also in part to underestimations in emissions of gaseous precursors of SOA and inaccurate meteorological predictions in 2010. The model also has significant biases for a few aerosol-cloud-radiation variables except for CF and QVAPOR; however, the model is able to reproduce the trends in aerosol-cloud-radiation variables for
2006 and 2010. The variation trends for most meteorological and chemical variables simulated by WRF and WRF/Chem are overall consistent with the observed trends from 2006 to 2010, but for $2010 \mathrm{WRF} / \mathrm{Chem}$ performs slightly worse than WRF. Similar to 2006, the inclusion of chemistrymeteorology feedbacks reduces NMBs for most meteorological variables in 2010, although WRF gives higher Corr and lower NME values than WRF/Chem.

A number of sensitivity simulations are also conducted for January and July 2006 and 2010 to quantify the relative impact of emissions, chemical ICONs/BCONs, and meteorology on model performance of major meteorological and chemical species as well as on the variation trends between 2006 and 2010. Using more accurate emissions and chemical and meteorological ICONs/BCONs will help improve the performance of some individual chemical and meteorological surface variables. Although the 2006 emissions may not represent the true emissions for 2010, the 2010 sensitivity simulations using the 2006 emissions show improved model performance. However, using 2006 emissions for 2010 simulations does not improve the degree of agreement with observed interannual trends as the consistency between the 2006 and 2010 emissions are affected between the simulations. The baseline simulations for 2006 and 2010 reproduce the observed trends the best, as a consistent set of 2006 and 2010 emissions are used. The current 2006 and 2010 emissions were developed taking into account the interannual trends; the improvement of emissions need to be carried out consistently for all individual simulation years when simulating multiyear cases.

WRF/Chem with the CB05-MADE/VBS option used in this work has been incorporated into the WRF/Chem version 3.6.1 to be released in version 3.7 of WRF-Chem (available for download at http://www.mmm.ucar.edu/wrf/users/). The results in this work indicate a need to further improve the accuracy of emissions and chemical BCONs, and the representations of organic aerosols and chemistry-meteorology feedbacks in WRF/Chem. In addition, the improvements in aerosol-cloud treatments, such as the aerosol activation parameterization, and in the microphysics and cumulus parameterizations that affect the formation of precipitation are needed to improve the model's capability in reproducing the state of the atmosphere and also interannual trends. While the long-term air quality simulations using WRF/Chem with aerosol-cloud-radiation feedbacks in this work can provide guidance on future model development and improvement, they do not provide the impact of those feedback mechanisms on the model performance. Quantifying such impacts requires another set of simulations using a version of WRF/Chem that does not treat aerosol direct and indirect effects, which is not yet available to public. The simulations with and without aerosol direct and indirect effects have indeed been performed by Makar et al. (2014a, b) using a different model that was specially designed to quantify such impacts. It would be useful to develop a version of WRF/Chem 
that does not treat aerosol direct and indirect effects for this impact assessment. In particular, a comparison of the episodic or long-term simulation results using WRF/Chem that includes and excludes feedback mechanisms against observations of aerosol and cloud variables can provide further insight into whether inclusion of those aerosol direct and indirect effects can improve the model's capability in reproducing observations. Those simulations should be considered when the version of WRF/Chem without aerosol direct and indirect effects and computer resources become available.

\section{The Supplement related to this article is available online at doi:10.5194/gmd-8-2095-2015-supplement.}

Acknowledgements. This study is funded by the National Science Foundation EaSM program (AGS-1049200) at NCSU. The following agencies have prepared the data sets used in this study: the U.S. EPA (North American emissions processing), Environment Canada, Mexican Secretariat of the Environment and Natural Resources (Secretaría del Medio Ambiente y Recursos Naturales, SEMARNAT) and National Institute of Ecology (Instituto Nacional de Ecología - INE) (North American national emissions inventories), the European Centre for Medium Range Weather Forecasting Global and Regional Earth-system (Atmosphere) Monitoring using Satellite and in situ data (ECMWF/GEMS) project and Meteo France/Centre national de recherches météorologiques (CNRMGAME) for the Monitoring Atmospheric Composition and Climate (MACC) ICONs/BCONs. Meteorological ICONs/BCONs are provided by the National Center for Environmental Protection. Ambient North American concentration measurements are provided by several US networks (AQS, CASTNET, IMPROVE, SEARCH, and STN). North American precipitation-chemistry measurements are provided by several US networks (CASTNET, and NADP). GPCC precipitation data are provided by the National Oceanic and Atmospheric Administration's Earth System Research Laboratory in the Physical Sciences Division (NOAA/OAR/ESRL PSD), Boulder, Colorado, USA, from their web site at http://www.esrl.noaa.gov/ psd/. The 2006 and 2010 SOA/OC data at RTP, NC, Bakersfield and Pasadena, CA, were provided by John Offenberg, U.S. EPA. Cloud variables were provided by MODIS. We thank Georg Grell, NOAA, Christian Hogrefe, US EPA, Paul Makar, Environment Canada, Christoph Knote, NCAR, and Patrick Campbell, NCSU, for helpful discussions on inputs and outputs of AQMEII model intercomparison. We would also like to acknowledge high-performance computing support from Yellowstone (ark:/85065/d7wd3xhc) provided by NCAR's Computational and Information Systems Laboratory, sponsored by the National Science Foundation and Information Systems Laboratory, sponsored by the National Science Foundation and Stampede, provided as an Extreme Science and Engineering Discovery Environment (XSEDE) digital service by the Texas Advanced Computing Center (TACC) (http://www.tacc.utexas.edu), which is supported by National Science Foundation grant number ACI - 1053575.

The US Environmental Protection Agency through its Office of Research and Development collaborated in the research described here. The manuscript has been subjected to external peer review and has been cleared for publication. Mention of trade names or commercial products does not constitute endorsement or recommendation for use.

Edited by: J. Williams

\section{References}

Abdul-Razzak, H. and Ghan, S. J.: A parameterization of aerosol activation, 2. Multiple aerosol types, J. Geophys. Res., 105, 68376844, 2000.

Ahmadov, R., McKeen, S. A., Robinson, A. L., Bahreini, R., Middlebrook, A. M., de Gouw, J. A., Meagher, J., Hsie, E.Y., Edgerton, E., Shaw, S., and Trainer, M.: A volatility basis set model for summertime secondary organic aerosols over the eastern United States in 2006, J. Geophys. Res., 117, D06301, doi:10.1029/2011JD016831, 2012.

Aitken, A. C., Decarlo, P. F., Kroll, J. H., Worsnop, D. R., Huffman, J. A., Docherty, K. S., Ulbrich, I. M., Mohr, C., Kimmel, J. R., Sueper, D., Sun, Y., Zhang, Q., Trimborn, A., Northway, M., Ziemann, P. J., Canagaratna, M. R., Onasch, T. B., Alfarra, M. R., Prevot, A. S. H., Dommen, J., Duplissy, J., Metzger, A., Baltensperger, U., and Jimenez, J. L.: O/C and OM/OC ratios of primary, secondary and ambient organic aerosols with high-resolution time-of-flight aerosol mass spectrometry, Environ. Sci. Technol., 42, 4478-4485, 2008.

Alapaty, K. V., Mathur, R., Pleim, J. E., Hogrefe, C., Rao, S. T., Ramaswamy, V., Galmarini, S., Schapp, M., Vautard, R., Makar, P., Baklanov, A., Kallos, G., Vogel, B., and Sokhi, R.: New Directions: Understanding interactions of air quality and climate change at regional scales, Atmos. Environ., 49, 419-421, 2012.

Baklanov, A., Schlünzen, K., Suppan, P., Baldasano, J., Brunner, D., Aksoyoglu, S., Carmichael, G., Douros, J., Flemming, J., Forkel, R., Galmarini, S., Gauss, M., Grell, G., Hirtl, M., Joffre, S., Jorba, O., Kaas, E., Kaasik, M., Kallos, G., Kong, X., Korsholm, U., Kurganskiy, A., Kushta, J., Lohmann, U., Mahura, A., Manders-Groot, A., Maurizi, A., Moussiopoulos, N., Rao, S. T., Savage, N., Seigneur, C., Sokhi, R. S., Solazzo, E., Solomos, S., Sørensen, B., Tsegas, G., Vignati, E., Vogel, B., and Zhang, Y.: Online coupled regional meteorology chemistry models in Europe: current status and prospects, Atmos. Chem. Phys., 14, 317-398, doi:10.5194/acp-14-317-2014, 2014.

Campbell, P., Zhang, Y., Yahya, K., Wang, K., Hogrefe, C., Pouliot, G., Knote, C., Hodzic, A., San Jose, R., Perez, J. L., Guerrero, P. J., Baro, R., and Makar, P.: A Multi-Model Assessment for the 2006 and 2010 Simulations under the Air Quality Model Evaluation International Initiative (AQMEII) Phase 2 over North America, Part I. Indicators of the Sensitivity of $\mathrm{O}_{3}$ and $\mathrm{PM}_{2.5}$ Formation to Precursor Gases, Atmos. Environ., doi:10.1016/j.atmosenv.2014.12.026, in press, 2014.

Chen, F.: The Noah Land Surface Model in WRF, A short tutorial, NCAR LSM group meeting, Boulder, CO, 17 April 2007.

Dawson, J. P., Racherla, P. N., Lynn, B. H., Adams, P. J., and Pandis, S. N.: Impacts of climate change on regional and urban air quality in the eastern United States: Role of meteorology. J. Geophys. Res., 114, D05308, doi:10.1029/2008JD009849, 2009. 
Edwards, J. M., Beare, R. J., and Lapworth, A. J.: Simulation of the observed evening transition and nocturnal boundary layers: single column modeling, Q. J. R. Meteorol. Soc., 132, 61-80, 2006.

Gao, Y., Fu, J. S., Drake, J. B., Liu, Y., and Lamarque, J.-F.: Projected changes of extreme weather events in the eastern United States based on a high resolution climate modeling system, Environ. Res. Lett., 7, 044025, doi:10.1088/1748-9326/7/4/044025, 2012.

Gao, Y., Fu, J. S., Drake, J. B., Lamarque, J.-F., and Liu, Y.: The impact of emission and climate change on ozone in the United States under representative concentration pathways (RCPs), Atmos. Chem. Phys., 13, 9607-9621, doi:10.5194/acp-13-96072013, 2013.

Grundstein, A. and Dowd, J.: Trends in extreme apparent temperatures over the United States, 1949-2010, J. Appl. Meteor. Climatol., 50, 1650-1653, 2011.

Hogrefe, C., Lynn, B., Civerolo, K., Ku, J.-Y., Rosenthal, J., Rosenzweig, C., Goldberg, R., Gaffin, S., Knowlton, K., and Kinney, P. L.: Simulating changes in regional air pollution over the eastern United States due to changes in global and regional climate and emissions, J. Geophys. Res., 109, D22301, doi:10.1029/2004JD004690, 2004.

Hogrefe, C., Pouliot, G., Wong, D., Torian, A., Roselle, S., Pleim, J., and Mathur, R.: Annual application and evaluation of the online coupled WRF-CMAQ system over North America under AQMEII Phase 2, Atmos. Environ., doi:10.1016/j.atmosenv.2014.12.034, in press, 2014.

Huber, D. G. and Gulledge, J.: Extreme weather and climate change: Understanding the link and managing the risk, Center for Climate and Energy Solutions, available at: http://www.c2es.org/ publications/extreme-weather-and-climate-change (last access: 6 July 2015), 2011.

Im, U., Bianconi, R., Solazzo, E., Kioutsioukis, I., Badia, A., Balzarini, A., Baro, R., Bellasio, R., Brunner, D., Chemel, C., Curci, G., Flemming, J., Forkel, R., Giordano, L., JimenezGuerrero, P., Hirtl, M., Hodzic, A., Hozak, L., Jorba, O., Knote, C., Kuenen, J. J. P., Makar, P. A., Manders-Groot, A., Neal, P., Perez, J. L., Pirovano, G., Pouliot, G., San Jose, R., Savage, N., Schroder, W., Sokhi, R.S., Syrakov, D., Torian, A., Tuccella, P., Werhahn, J., Wolke, R., Yahya, K., Zabkar, R., Zhang, Y., Zhang, J., Hogrefe, C., and Galmarini, S.: Evaluation of operational online-coupled regional air quality models over Europe and North America in the context of AQMEII phase 2. Part 1: Ozone, Atmos. Environ., doi:10.1016/j.atmosenv.2014.09.042, in press, 2014.

IPCC: Climate change 2007: the physical science basis, in: Contribution of Working Group I to the Fourth Assessment Report of the Intergovernmental Panel on Climate Change, edited by: Solomon, S., Qin, D., and Manning, M., 2007.

IPCC: Managing the risks of extreme events and disasters to advance climate change adaptation (SREX), A special report of Working Groups I and II of the Intergovernmental Panel on Climate Change, edited by: Field, C. B., Barros, V., Stocker, T. F., Qin, D., Dokken, D. J., Ebi, K. L., Mastrandrea, M. D., Mach, K. J., Plattner, G.-K., Allen, S. K., Tignor, M., and Midgley, P. M., Cambridge University Press, Cambridge, UK, and New York, NY, USA, 582 pp., 2012.
Jacob, D.: Heterogeneous chemistry and tropospheric ozone, Atmos. Environ., 34, 2131-2159, 2000.

Jin, J., Miller, N. M., and Schlegel, N.: Sensitivity study of four land surface schemes in the WRF model, Adv. Meteorol., 167436, 11 pp., doi:10.1155/2010/167436, 2010.

Khiem, M., Ooka, R., Huang, H., Hayami, H., Yoshikado, H., and Kawamoto, Y.: Analysis of the relationship between changes in meteorological conditions and the variation in summer ozone levels over the central Kanto area, Adv. Meteorol., 349248, 13 pp., doi:10.1155/2010/349248, 2010.

Leung, L. and Gustafson, W.: Potential regional climate change and implications to US air quality, Geophys. Res. Lett., 32, L16711, doi:10.1029/2005GL022911, 2005.

Lewandowski, M., Piletic, I. R., Kleindienst, T. E., Offenberg, J. H., Beaver, M. R., Jaoui, M., Docherty, K. S., and Edney, E. O.: Secondary organic aerosol characterization at field sites across the United States during the spring-summer period, Int. J. Environ. Anal. Chem., 93, 1084, doi:10.1080/03067319.2013.803545, 2013.

Makar, P., Gong, W., Milbrandt, J., Hogrefe, C., Zhang, Y., Curci, G., Zabkar, R., Im, U., Balzarini, A., Baro, R., Bianconi, R., Cheung, P., Forkel, R., Gravel, S., Hirtl, M., Honzak, L., Hou, A., Jimenez-Guerrero, P., Langer, M., Moran, M. D., Pabla, B., Perez, J. L., Pirovano, G., San Jose, R., Tuccella, P., Werhahn, J., Zhang, J., and Galmarini, S.: Feedbacks between air pollution and weather, part 1: Effects on weather, Atmos. Environ., doi:10.1016/j.atmos.env.2014.12.003, in press, 2014a.

Makar, P., Gong, W., Hogrefe, C., Zhang, Y., Curci, G., Zabkar, R., Milbrandt, J., Im, U., Balzarini, A., Baro, R., Bianconi, R., Cheung, P., Forkel, R., Gravel, S., Hirtl, M., Honzak, L., Hou, A., Jimenez-Guerrero, P., Langer, M., Moran, M. D., Pabla, B., Perez, J. L., Pirovano, G., San Jose, R., Tuccella, P., Werhahn, J., Zhang, S., and Galmarini, S.: Feedbacks bewteen air pollution and weather, part 2: Effects on chemistry, Atmos. Environ., doi:10.1016/j.atmosenv.2014.10.021, in press, 2014b.

Mass, C. and Owens, D.: WRF Model Physics: Progress, problems and perhaps some solutions, Presented at the 11th WRF Users' Workshop, Boulder, CO, 21-25 June 2010.

Meir, T., Orton, P. M., Pullen, J., Holt, T., Thompson, W. T., and Arend, M. F.: Forecasting the New York City urban heat island and sea breeze during extreme heat events, Weather Forecast., 28, 1460-1477, 2013.

Odum, J. R., Hoffmann, T., Bowman, F., Collins, D., Flagan, R. C., and Seinfeld, J. H.: Gas/Particle partitioning and secondary organic aerosol yields, Environ. Sci. Technol., 30, 2580-2585, 1996.

Offenberg, J. H., Lewandowski, M., Jaoui, M., and Kleindienst, T. E.: Contributions of biogenic and anthropogenic hydrocarbons to secondary organic aerosol during 2006 in Research Triangle Park, NC, Aero. Air Qual. Res., 11, 99-108, 2011.

Oswald, E. M. and Rood, R. B.: A trend analysis of the 1930-2010 extreme heat events in the continental United States, J. Appl. Meteor. Climatol., 53, 565-582, 2014.

Penrod, A., Zhang, Y., Wang, K., Wu, S.-Y., and Leung, R. L.: Impacts of Future Climate and Emission Changes on U.S. Air Quality, Atmos. Environ., 89, 533-547, 2014.

Pleim, J. E. and Gilliam, R.: An Indirect Data Assimilation Scheme for Deep Soil Temperature in the Pleim-Xiu Land 
Surface Model, J. Appl. Meteor. Climatol., 48, 1362-1376, doi:10.1175/2009JAMC2053.1, 2009.

Pouliot, G., van der Gon, H. D., Kuenen, J., Makar, P., Zhang, J., and Moran, M.: Analysis of the Emission Inventories and Model-Ready Emission Datasets of Europe and North America for Phase 2 of the AQMEII Project, Atmos. Environ., doi:10.1016/j.atmosenv.2014.10.061, in press, 2014.

Rao, S., Galmarini, S., and Steyn, D. G.: AQMEII: An International Initiative for the Evaluation of Regional-Scale Air Quality Models-Phase 1, Atmos. Environ., Special Issue, 53, 1-224, 2012.

Reid, J. S., Koppmann, R., Eck, T. F., and Eleuterio, D. P.: A review of biomass burning emissions part II: intensive physical properties of biomass burning particles, Atmos. Chem. Phys., 5, 799825, doi:10.5194/acp-5-799-2005, 2005.

Sarwar, G., Fahey, K., Napelenok, S., Roselle, S., and Mathur, R.: Examining the impact of CMAQ model updates on aerosol sulfate predictions, 10th Annual CMAQ Models-3 Users's Conference, Chapel Hill, NC, 2011.

Schell, B., Ackermann, I. J., Hass, H., Binkowski, F. S., and Ebel, A.: Modeling the formation of secondary organic aerosol within a comprehensive air quality model system, J. Geophys. Res., 106, 28275-28293, 2001.

Schere, K, Flemming, J., Vautard, R., Chemel, Colette, A., Hogrefe, C., Bessagnet, B., Meleux, F., Mathur, R., Roselle, S., Hu, R.M., Sokhi, R. S., Rao, S. T., and Galmarini, S.: Trace gas/aerosol boundary concentrations and their impacts on continental-scale AQMEII modeling domains, Atmos. Environ., 53, 38-50, 2012.

Stoeckenius, T., Chemel, C., Zagunis, J., and Sakulyanontvittaya, T.: A Comparison between 2010 and 2006 Air Quality and Meteorological Conditions, and Emissions and Boundary Conditions for the AQMEII-2 North American Domain, Atmos. Environ., doi:10.1016/j.atmosenv.2015.02.043, in press, 2015.

Van Lier-Walqui, M., Vukicevic, T., and Posselt, D. J.: Linearization of microphysical parameterization uncertainty using multiplicative process perturbation parameters, Mon. Weather Rev., 142, 401-413, 2014.

Wang, J. and Kotamarthi, V. R.: Downscaling with a nested regional climate model in near-surface fields over the contiguous United States, J. Geophys. Res. Atmos., 119, 8778-8797, doi:10.1002/2014JD021696, 2014.

Wang, K., Yahya, K., Zhang, Y., Wu, S.-Y., and Grell, G.: Implementation and Initial Application of A New ChemistryAerosol Option in WRF/Chem for Simulation of Secondary Organic Aerosols and Aerosol Indirect Effects, Atmos. Environ., doi:10.1016/j.atmosenv.2014.12.007, in press, 2014.
Wu, J. and Zhang, M.: Simulations of clouds and sensitivity study by Weather Research and Forecast Model for Atmospheric Radiation Measurement case 4, Fifteenth Arm Science Team Meeting Proceedings, 14-18 March 2005, Daytona Beach, FL, 2005.

Xing, J., Pleim, J., Mathur, R., Pouliot, G., Hogrefe, C., Gan, C.-M., and Wei, C.: Historical gaseous and primary aerosol emissions in the United States from 1990 to 2010, Atmos. Chem. Phys., 13, 7531-7549, doi:10.5194/acp-13-7531-2013, 2013.

Yahya, K., Wang, K., Gudoshava, M., Glotfelty, T., and Zhang, Y.: Application of WRF/Chem over the continental U.S. under the AQMEII Phase II Part 1: Comprehensive Evaluation of 2006 Simulation, Atmos. Environ., doi:10.1016/j.atmosenv.2014.08.063, in press, 2014.

Yang, B., Qian, Y., Lin, G., Leung, L. R., Rasch, P. J., Zhang, G. J., McFarlane, S. A., Zhao, C., Zhang, Y., Wang, H., Wang, M., and Liu, X.: Uncertainty quantification and parameter running in the CAM5 Zhang-McFarlane convection scheme and impact of improved convection on the global circulation and climate, J. Geophys. Res., 118, 395-415, 2013.

Zhang, Y.: Online-coupled meteorology and chemistry models: history, current status, and outlook, Atmos. Chem. Phys., 8, 28952932, doi:10.5194/acp-8-2895-2008, 2008.

Zhang, Y., Hu, X., Leung, L. R., and Gustafson Jr., W. I.: Impacts of regional climate change on biogenic emissions and air quality, $\mathrm{J}$. Geophys. Res., 113, D18310, doi:10.1029/2008JD009965, 2008.

Zhang, Y., Wen, X.-Y., and Jang, C. J.: Simulating chemistryaerosol-cloud-radiation-climate feedbacks over the continental U.S. using the online-coupled Weather Research Forecasting Model with chemistry (WRF/Chem), Atmos. Environ., 44, 3568-3582, 2010.

Zhang, Y., Chen, Y.-C., Sarwar, G., and Schere, K.: Impact of Gas-Phase Mechanisms on Weather Research Forecasting Model with Chemistry (WRF/Chem) Predictions: Mechanism Implementation and Comparative Evaluation, J. Geophys. Res., 117 D01301, doi:10.1029/2011JD015775, 2012.

Zhang, Y., Wang, W., Wu, S.-Y., Wang, K., Minoura, H., and Wang, Z.-F.: Impacts of Updated Emission Inventories on Source Apportionment of Fine Particle and Ozone over the Southeastern U.S., Atmos. Environ., 588, 133-154, 2014. 